\title{
Sourcing Product Quality for Foreign Market Entry*
}

\author{
Onur A. Koska ${ }^{\dagger}$
}

July 10, 2019

\begin{abstract}
This study employs a differentiated Cournot model with both horizontal and vertical product differentiation. It scrutinizes the implications of frictions over manufacturing high quality (upstream market power) on the endogenous foreign market entry mode and product quality choice. Both high-quality exports and subsidiary sales require high-quality inputs supplied by a monopoly upstream firm, and thus are costly. Relative product quality, product substitutability, and product-specific trade costs are the key for the variation in input/output prices, sales and the markup between an exporter and a multinational, and have significant trade policy implications for high-quality exports and subsidiary sales.
\end{abstract}

Keywords: Vertical Product Differentiation; Horizontal Product Differentiation; Upstream Market Power; Trade; Foreign Direct Investment

JEL Classification: F23

*This paper has been presented at the Australasian Trade Workshop (ATW) in Melbourne, at Mainz Workshop on FDI \& Multinational Corporations in Mainz, at the University of Tuebingen (Germany), and at the University of Canterbury (New Zealand). I am grateful to participants for useful comments and suggestions. Declarations of interest: none

${ }^{\dagger}$ University of Canterbury, Department of Economics and Finance, Private Bag 4800, Christchurch 8140 New Zealand. Tel: +64 33690842 Email: onur.koska@canterbury.ac.nz 


\section{Introduction}

It is widely reported in the empirical trade literature that changes in international trade costs substantially affect firm-level decisions on trade, on foreign direct investment (FDI), and on both horizontal and vertical product differentiation; see Atkeson and Burstein (2010). Modeling both horizontal and vertical product differentiation in a differentiated Cournot duopoly market, this study scrutinizes the implications of upstream market power (for high-quality inputs) on a downstream firm's endogenous choice of foreign market entry mode and product quality. The endogenous choice of product quality is modeled as the choice of an input supplier. While low-quality inputs are provided by a perfectly competitive upstream industry and lead to low-quality differentiated products, both high-quality exports and subsidiary sales (the latter of which warrants also vertical intra-industry trade) require high-quality inputs supplied by a monopoly upstream firm, and thus are costly. In such an environment, the paper delineates (i) different incentives of exporters and multinationals to penetrate foreign markets by high-quality products; (ii) variation in input/output prices, sales and markups between exporters and multinationals; and (iii) how firm-level decisions on the foreign market entry mode and on the input choice change with changes in relative quality among varieties, in the degree of product substitutability and in product-specific trade and transport costs.

There is a large and rapidly growing trade literature relating variation in firm-level decisions to firm heterogeneity. One strand of this literature focuses on heterogeneity in firm productivity (e.g., Melitz, 2003; Helpman et al., 2004), and its implications on firm-level decisions (including the optimal foreign market entry mode). In particular, firms' investments in $\mathrm{R} \& \mathrm{D}$, and their intensive use of professional and technical workers are considered the main source of firm-level economies of scale leading to heterogeneity at the firm level. The related empirical literature has shown that multinationals are well represented in capital-intensive and $R \& D$-intensive industries ${ }^{1}$ and that there is sorting by productivity: multinationals are, on average, more productive than exporting firms which are themselves more productive than firms serving only domestic markets. ${ }^{2}$

\footnotetext{
${ }^{1}$ See, for instance, Antràs and Yeaple (2014) for U.S. multinationals, Mayer and Ottaviano (2008) for French, German, Norwegian and Belgian multinationals, and Navaretti and Venables (2004) for French, German, Japanese, British and U.S. multinationals.

${ }^{2}$ See Antràs and Yeaple (2014), Castellani and Giovannetti (2010), Arnold and Hussinger (2010), Aw and Lee (2008), Mayer and Ottaviano (2008), Castellani and Zanfei (2007), Tomiura (2007), Kimura and Kiyota (2006), Wagner (2006), Girma et al. (2005; 2004), and Helpman et al. (2004). For a review of the literature, see Hayakawa et al. (2012), Wagner (2012; 2007), and Greenaway and Kneller (2007).
} 
While the literature on heterogeneity in firm productivity, to some extent, also studies horizontal product differentiation, vertical (quality) differentiation is, by and large, assumed away. In general, the related literature has shown that (i) multinationals' products can be characterized by higher sophistication (Markusen, 2002; Navaretti and Venables, 2004); (ii) an exporter's cost disadvantage (when competing against a local firm) leads to a less competitive product specification, whereas a multinational may prefer a more aggressive one (De Fraja and Norman, 2004); and that (iii) trade liberalization increases exporters' incentives to invest more in product differentiation (Schmitt, 1995; Braun, 2008; Bastos and Straume, 2012).

Another strand of the trade literature models heterogeneity in product quality so as to explain the significantly high share of intra-industry trade in vertically differentiated products and variation in unit values (among firms, or within firms, across destinations, etc.) with vertical product differentiation. ${ }^{3}$ For instance, Anderson and Schmitt (2010) report a significantly high share of intra-industry trade in vertically differentiated products (e.g., $40 \%$ in the EU) and explain this with asymmetric trade liberalization in a general equilibrium trade model. In particular, the related trade literature has reported a strong positive correlation between unit values and product quality; see, for example, Verhoogen (2008); Kugler and Verhoogen (2012); Manova and Zhang (2012); Crozet et al. (2012); Feenstra and Romalis (2014). This strand of the literature argues that product quality can be related to firm productivity (e.g., Baldwin and Harrigan, 2011; Kugler and Verhoogen, 2012), and that (i) higher productivity firms tend to be larger in terms of sales; (ii) tend to use higher quality inputs and pay more for their inputs; (iii) tend to produce higher quality products; and thus (iv) tend to charge higher prices for their exports; for empirical evidence, see Hallak and Sivadasan (2013) using Indian data; Kugler and Verhoogen (2012) using Colombian data; Manova and Zhang (2012) using Chinese data.

Building on these different strands of the trade and FDI literature, this study would like to complement and contribute to the existing literature in the following ways. Most studies in the related literature rely on nonhomothetic demands, or heterogeneity in consumer preferences/tastes (so as to capture vertically differentiated traded products),

\footnotetext{
${ }^{3}$ Vertical differentiation can be traced back to Linder (1961) and Alchian and Allen (1964). For the related trade literature on vertical product differentiation see, among others, Falvey and Kierzkowski (1987), Flam and Helpman (1987), Motta et al. (1997), Toshimutsu (2005), Iacovone and Javorcik (2010), Anderson and Schmitt (2010), Verhoogen (2008), Johnson (2012), Bastos and Silva (2010), Baldwin and Harrigan (2011), Fajgelbaum et al. (2011), Kugler and Verhoogen (2012), Crozet et al. (2012), Manova and Zhang (2012), Amiti and Khandelwal (2013), Antoniades (2015), Feenstra and Romalis (2014), Bacchiega et al. (2016), Manova and Yu (2017).
} 
which can be argued to be relevant to certain markets.4 This study, however, looks into another empirically relevant market segment, simply by focusing on a representative consumer's preferences (for both vertically and horizontally differentiated varieties) represented by a quality-augmented quadratic utility function. The main motivation behind this is the observation that many households demand (horizontally) differentiated products of different qualities at the same time (e.g., households with multiple cars and TV-sets of different qualities etc.). Following the related literature, while this paper also assumes that maintaining high quality warrants quality inputs (e.g., Kugler and Verhoogen, 2012; Hallak and Sivadasan, 2013) and is costly, it takes a different approach and models that not all firms are able to manufacture high quality and there are large frictions against quality upgrading.

The existing trade and FDI literature on vertical product differentiation simplifies firms' input quality choices and focuses mainly on fixed and/or variable costs of manufacturing high quality. $\left.\right|^{5}$ This study, however, shows that a number of intuitive results can be obtained by explicitly modeling both the input choice and frictions against quality manufacturing. While there are certainly different ways to capture different aspects of such frictions, the innovation of this study is that it models a potential downstream exporter's and a multinational's input choice under upstream market power. In particular, the paper considers quality inputs that are highly customized (according to the needs of a final good producer), and thus are not sold on an organized exchange, nor are they reference priced in trade publications $\sqrt[6]{6}$ They are rather produced by a monopoly upstream firm generating frictions by exercising market power, which renders the high quality manufacture costly. The empirical motivation is the observation that the share of differentiated and customized input trade in world trade has increased substantially, as emphasized by Antrás and Staiger (2012). The related literature predominantly

\footnotetext{
${ }^{4}$ Such trade models can be strongly related to the models by Mussa and Rosen (1978), Gabszewicz and Thisse (1979), Shaked and Sutton (1982), Tirole (1988), Choi and Shin (1992), Motta (1993), Crampes and Hollander (1995), Kim and Kim (1996), Wauthy (1996), and Acharyya (1998; 2005).

${ }^{5}$ Toshimutsu (2005) shows that if costs of quality improvements are of variable (fixed) type and increasing, then a decrease in imports - by a higher specific tariff - leads to quality upgrading (downgrading). By the same token, in a heterogeneous firm model, Antoniades (2015) finds that when quality costs are of fixed type, an increase in market toughness generates two opposing forces, a competition effect (decreasing prices, markups and quality) and a quality-differentiation effect (increasing those). The former (latter) dominates for the least (most) productive firms.

${ }^{6}$ The trade literature distinguishes among inputs that are sold on an exchange (such that the market for the input is thick with many buyers and sellers), those that are not, but reference priced in trade publications (such that their market has an intermediate level of thickness), and those that are neither sold on an exchange, nor reference priced (such that they are highly specialized); see, for example, Rauch (1999) and Nunn (2007).
} 
focuses on contract enforcement for highly customized inputs so as to address an important aspect of such frictions and its implication on exporters' and multinationals' decisions; see, among others, Antrás (2003), Antrás and Helpman (2004), Antrás and Staiger (2012) and Antrás (2016), and references therein. This study thus complements the related literature by focusing on another important aspect of such frictions, that is, upstream market power in customized high-quality inputs. Thus modeling frictions from a different and novel perspective, (i) it provides a further theoretical background and intuition explaining and qualifying empirical results reported in the related trade literature (in regards to vertical differentiation and trade); and (ii) it extends discussions to also multinationals and FDI.

The existing literature focuses mainly on exporters and importers in the context of vertical product differentiation.7 This study thus complements and contributes to the existing literature by delineating incentives for both exporters and multinationals. By allowing for both vertical and horizontal product differentiation in a differentiated Cournot market, this study focuses on the role upstream market power can play for a downstream foreign firm's market entry mode choice (trade or FDI) along with its product quality choice (via choosing a particular input supplier). The downstream firm has the option to procure high-quality inputs (so as to produce a differentiated highquality final good) from a monopoly upstream firm located in Home, or to rely on a standard input (leading to a differentiated low-quality final good) from a perfectly competitive upstream industry (either in Home or Foreign) when entering a foreign market. Upstream market power for high-quality inputs renders production of a differentiated high-quality final good costly and leads to double marginalization. That said, product quality improves foreign market access. The downstream firm has to bear perunit trade costs in the case of exporting the final good to Foreign from Home, which can be avoided by undertaking FDI. FDI, however, requires fixed investments costs, and if the downstream firm decides to procure high-quality inputs from Home, then in addition to fixed FDI costs, it has to pay per-unit trade costs to transfer such inputs to Foreign (i.e., costs of vertical intra-industry trade).

Relative product quality, the degree of product substitutability and product-specific trade costs (i) are the key for variation in input/output prices, sales and the markup between an exporter and a multinational; (ii) are important factors affecting a firm's

\footnotetext{
${ }^{7}$ There are a few papers relying on heterogeneity in consumer preferences so as to model vertical differentiation and scrutinizing the choice between trade and FDI; see, for example, Motta (1994) in the context of a single-product firm, and Mai and Zhou (2017) in the context of a multi-product firm.
} 
optimal foreign market entry mode and product quality choices; and (iii) have significant policy implications for high-quality exports and subsidiary sales. The model is simple and generates a rich set of some intuitive results. For instance, according to the results, decreasing the degree of product substitutability can undermine positive economic virtues of costly quality upgrading, irrespective of the foreign market entry mode, whereas trade and transport costs have a more involved role. Decreasing trade and/or transport costs in final goods can promote high-quality exports against low-quality subsidiary sales especially if relative quality is sufficiently high, which is supported in equilibrium even for zero fixed investment costs. ${ }^{8}$ If, however, relative quality is sufficiently low, decreasing trade and/or transport costs in final goods only leads to quality downgrading by an exporter, while low-quality subsidiary sales dominate in equilibrium irrespective of trade and transport costs, so long as fixed investment costs are also sufficiently low. In contrast, decreasing input trade and transport costs can lead to quality upgrading by a subsidiary. If input trade and transport costs decrease faster than those in final goods, then in equilibrium, high-quality vertical intra-industry trade and subsidiary sales can be promoted against high-quality exports so long as relative quality is high and fixed investment costs are sufficiently low. In particular, it can be argued that according to results, there is some scope for using trade policy as an instrument of quality control, especially when relative quality is sufficiently high. While free trade in final goods supports high-quality exports, free trade in inputs can support both highquality exports and subsidiary sales such that consequently, the level of fixed costs will determine the equilibrium foreign market entry mode. Also the model is extended to vertical integration, which clearly shows that double marginalization due to upstream market power generates significant frictions and makes manufacturing high quality less likely for both multinationals and exporters (in terms of both fixed investment costs and trade costs in both inputs and final goods).

The rest of the paper is organized as follows. Section 2 introduces the model. Section 3 scrutinizes the optimal sourcing decisions (the product quality choice) of an exporter and a multinational. Section 4 solves the model for the equilibrium foreign market entry mode. Section 5 extends the model to vertical integration and delineates the optimal behavior of the integrated firm. Finally, Section 6 concludes the study. For convenience, most of the proofs and technical details are relegated to the Appendix.

\footnotetext{
${ }^{8}$ Note that when trade costs are positive and there is no fixed investment costs, traditional FDI models with vertically homogeneous goods predict horizontal FDI (that duplicates the production process in a foreign country) as the optimal foreign market entry mode based on the proximity-concentration trade-off; e.g., see Koska (2015).
} 


\section{The model}

This study employs a simple differentiated Cournot duopoly model. There are two countries: Home $(H)$ and Foreign $(F)$. There is one downstream firm in each country, namely firms $h$ and $f$ located, respectively, in $H$ and in $F$. Both countries have perfectly competitive upstream industries producing a (standard) low-quality input with zero marginal cost. In addition, $H$ has also a monopoly upstream firm producing a high-quality input with zero marginal cost. This asymmetry (in terms of upstream industries) between $H$ and $F$ follows the observation that a significant number of countries suffers severely from the lack of resources to generate physical, intellectual and business know-how (e.g., see Banarjee and Noyak, 2017), and that manufacturing high-quality inputs/output warrants the use of technologically advanced and sufficient physical, human and knowledge capital (e.g., see Manova and Zhang, 2012). Also consistent with this, firm $f$ is technologically constrained, and thus uses a low-quality input and only serves $F$ by a low-quality product. The idea that firm $f$ does not serve $H$ by its low-quality product is also empirically relevant as some countries (e.g., Japan, the USA, and the EU) have strict quality standards on imports. For example, Nabin et al. (2013) report that Chinese automakers (failing some certain crash tests) were not able to penetrate European markets for long years, or that Indonesian shrimp producers (lacking some expertise, and thus had to rely on traditional methods) were not able to meet the zero-chloramphenicol requirement of the EU. This study thus focuses only on firm $h$ 's market entry in $F$.

Firm $h$ can serve $F$ either by exports, or via FDI. Exports require per-unit trade and transport costs in final goods (denoted $\tau$ ), which can be avoided by undertaking FDI and paying fixed FDI costs (denoted $G$ ). Moreover, firm $h$ can source inputs either from a perfectly competitive upstream industry (either in $H$ or in $F$ ) and produce a low-quality product, or from the monopoly upstream firm in $H$ and produce a highquality product. If firm $h$ decides to manufacture high quality in the case of FDI, then it has to pay also per-unit trade and transport costs (denoted $t$ ) to transfer high-quality inputs to $F .9$ After having obtained inputs (denoted $z$ ), firms can produce the final good (denoted $x$ ) according to production function $f(z)$ without any further cost (input prices are the only production costs for the firms) such that $x_{i}=f(z)=z, i=\{h, f\}$.

\footnotetext{
${ }^{9}$ Note that this study does not model the transport sector, and thus does not distinguish between tariffs and transport costs. See Boddin and Stähler (2018) for a model that scrutinizes the transport sector exercising market power. In this study, both $t, \tau$ and $G$ are given, and throughout the paper, trade-related costs (e.g., tariffs and transport costs) are referred to as trade costs.
} 
Manufacturing high quality is costly due to upstream market power: high-quality input price $p_{z}$ is solely determined by the upstream monopoly.

The demand side of the model borrows from Singh and Vives (1984), Häckner (2000) and Symeonidis (2003), and considers a continuum of consumers of the same type with a utility function that is separable and linear in the numeraire good (composite goods) $M$ and quadratic and strictly concave in the consumption of differentiated $x$-goods. In particular, the representative consumer maximizes

$$
U\left(x_{h}, x_{f}, M\right)=u_{h} x_{h}+u_{f} x_{f}-x_{h}^{2} / 2-x_{f}^{2} / 2-\sigma x_{h} x_{f}+M
$$

with respect to the budget constraint $\sum_{i} p_{i} x_{i}+M \leq Y$, where $Y$ is income, $p_{i}$ denotes the price of differentiated good $i=\{h, f\}$, and the price of the composite good is normalized to one. The degree of product substitutability is measured by $\sigma \in(0,1)$ and interpreted in terms of horizontal product differentiation as the goods are substitutes. ${ }^{10}$ Vertical product differentiation is measured by $u_{i}, i=\{h, f\}$, such that $u_{i}$ is interpreted in terms of product quality in a vertical sense.11

The first-order condition of the utility maximization problem

$$
\frac{\partial U(\cdot)}{\partial x_{i}}: u_{i}-x_{i}-\sigma x_{j}-p_{i}=0, \quad i \neq j \in\{h, f\}
$$

leads to the optimal consumption of each variety $i=\{h, f\}$ of $x$-good, such that

$$
x_{i}\left(p_{i}, p_{j}\right)=\frac{\left(u_{i}-p_{i}-\sigma\left(u_{j}-p_{j}\right)\right)}{\left(1-\sigma^{2}\right)}, \quad i \neq j \in\{h, f\} \text {, }
$$

in the region $\left\{p \in R_{+}^{2}: u_{h}-p_{h}-\sigma\left(u_{f}-p_{f}\right)>0, u_{f}-p_{f}-\sigma\left(u_{h}-p_{h}\right)>0\right\}$ where the inverse demand function is linear for each variety $i$ and can be expressed as

$$
p_{i}\left(x_{i}, x_{j}\right)=u_{i}-x_{i}-\sigma x_{j}, \quad i \neq j \in\{h, f\} .
$$

It is clear that demand for variety $i$ of $x$-good is always downward sloping in its own price and increases with an increase in the price of the rival's variety.

As for the supply side, the structure is as follows: (i) Firm $h$ chooses the optimal foreign market entry mode (exports or FDI); then (ii) it decides on the input type (high quality

\footnotetext{
${ }^{10}$ Each firm's market power increases as $\sigma$ decreases such that if $\sigma=0$, then each firm would have monopolistic market power, whereas products would be perfect substitutes when there is no vertical differentiation between the varieties and when $\sigma=1$.

${ }^{11} \mathrm{An}$ increase in $u_{i}$ ceteris paribus increases the marginal utility of good $i=\{h, f\}$.
} 
or low quality) for production by choosing its supplier ${ }^{12}$ and finally (iii) both firms ( $h$ and $f$ ) compete in a differentiated Cournot duopoly market in $F$. The model is solved backwards.

In the last stage (in differentiated Cournot duopoly), each firm maximizes its own profit, $\pi_{i}=\left(p_{i}\left(x_{i}, x_{j}\right)-c_{i}\right) x_{i}, i \neq j \in\{h, f\}$ by simultaneously choosing quantities $x_{i}, i \in\{h, f\}$. From the first-order condition of the profit maximization problem, each firm's reaction function can be expressed as

$$
x_{i}\left(x_{j}\right)=\frac{1}{2}\left(u_{i}-\sigma x_{j}-c_{i}\right), \quad i \neq j \in\{h, f\},
$$

which can be solved for optimal quantities set by each firm in equilibrium, such that solving $x_{h}^{*}=x_{h}\left(x_{f}^{*}\right)$ and $x_{f}^{*}=x_{f}\left(x_{h}^{*}\right)$ for $x_{h}^{*}$ and $x_{f}^{*}$ leads to

$$
x_{i}^{*}=\frac{\left(2\left(u_{i}-c_{i}\right)-\sigma\left(u_{j}-c_{j}\right)\right)}{\left(4-\sigma^{2}\right)}, \quad i \neq j \in\{h, f\},
$$

in the region of quality spaces where optimal quantities are positive. Using eq.(1), it is straightforward to show that $\partial x_{i} / \partial c_{i}<0, \partial x_{i} / \partial c_{j}>0$, and $\left|\partial x_{i} / \partial c_{i}\right|>\left|\partial x_{i} / \partial c_{j}\right|$, $i \neq j \in\{h, f\}$, that is, (i) an increase in the firm's own cost, or a decrease in the rival's cost, decreases the firm's sales; and (ii) the firm's sales are more responsive to changes in its own cost than the rival's cost. These marginal impacts, however, depend on the degree of product substitutability, such that $\partial^{2} x_{i} / \partial c_{i} \partial \sigma<0, \partial^{2} x_{i} / \partial c_{j} \partial \sigma>0$, and that $\left|\partial^{2} x_{i} / \partial c_{i} \partial \sigma\right|<\left|\partial^{2} x_{i} / \partial c_{j} \partial \sigma\right|, i \neq j \in\{h, f\}$, that is, (i) the marginal impacts of both the firm's own and the rival's costs on the firm's sales get weaker when the varieties are less substitutable (when $\sigma$ is lower); and (ii) this weakening effect is greater in the case of a change in the rival's costs.

It is also clear in eq. (1) that $\partial x_{i} / \partial u_{i}>0, \partial x_{i} / \partial u_{j}<0$ and $\left|\partial x_{i} / \partial u_{i}\right|>\left|\partial x_{i} / \partial u_{j}\right|$, $i \neq j \in\{h, f\}$, that is, (i) an increase in the firm's own product quality, or a decrease in the rival's product quality increases the firm's sales: ${ }^{13}$ and (ii) the firm's sales are more responsive to changes in its own product quality. These marginal impacts also depend on the degree of product substitutability, such that $\partial^{2} x_{i} / \partial u_{i} \partial \sigma>0, \partial^{2} x_{i} / \partial u_{j} \partial \sigma<0$, and that $\left|\partial^{2} x_{i} / \partial u_{i} \partial \sigma\right|<\left|\partial^{2} x_{i} / \partial u_{j} \partial \sigma\right|, i \neq j \in\{h, f\}$, that is, (i) the marginal impacts of both the firm's own and the rival's product quality on the firm's sales get weaker

\footnotetext{
${ }^{12}$ Changing the sequence such that product quality is chosen before the market entry mode will not change the results, but will complicate the exposition of the model.

${ }^{13}$ More precisely, manufacturing higher quality has two effects: a direct demand effect that increases sales, and an indirect cost effect that decreases sales by increasing production costs. As will be clear in the following sections, the direct effect dominates for both exporters and multinationals.
} 
when the varieties are less substitutable (when $\sigma$ is lower); and (ii) this weakening effect is greater in the case of a change in the rival's product quality. Note that while product quality and costs affect sales in opposite directions, the magnitudes of the marginal impacts are the same (i.e., $\left|\partial x_{i} / \partial c_{i}\right|=\left|\partial x_{i} / \partial u_{i}\right|, i=\{h, f\}$, and $\left|\partial x_{i} / \partial c_{j}\right|=\left|\partial x_{i} / \partial u_{j}\right|$, $i \neq j \in\{h, f\})$ : decreasing costs will have the same affect on sales as increasing quality, so long as the indirect cost effect of a change in quality is negligible. This can be regarded as a support for the argument in Atkeson and Burstein (2010) that a firm's productivity can be interpreted as its product quality, such that the firm innovates to improve quality rather than to increase productivity.

Substituting the optimal sales given by eq.(1) into the inverse demand function gives the equilibrium price of each variety, such that

$$
p_{i}^{*}=\frac{\left(2 u_{i}+\left(2-\sigma^{2}\right) c_{i}-\sigma\left(u_{j}-c_{j}\right)\right)}{\left(4-\sigma^{2}\right)}, \quad i \neq j \in\{h, f\} .
$$

Using eq.(2), it is straightforward to show that $\partial p_{i} / \partial c_{i}>\partial p_{i} / \partial c_{j}>0, i \neq j \in\{h, f\}$, that is, (i) an increase in the firm's own cost, or in the rival's cost, increases the price of the firm's own variety; and (ii) the firm's own price is more responsive to changes in its own cost than the rival's cost. These marginal impacts, however, depend on the degree of product substitutability, such that $\partial^{2} p_{i} / \partial c_{i} \partial \sigma<0, \partial^{2} p_{i} / \partial c_{j} \partial \sigma>0$, and that $\left|\partial^{2} p_{i} / \partial c_{i} \partial \sigma\right|<\left|\partial^{2} p_{i} / \partial c_{j} \partial \sigma\right|, i \neq j \in\{h, f\}$, that is, (i) when the varieties are less substitutable (when $\sigma$ is lower), the marginal impact of the firm's own cost on its own price gets stronger, whereas the marginal impact of the rival's cost on the firm's own price gets weaker; and (ii) these second-order effects are greater in the case of a change in the rival's costs. The following remarks are in order: (i) when the products are less related, an increase in the firm's own cost is reflected more on the consumers; (ii) an increase in the rival's cost increases the firm's sales (which decreases the firm's price), while decreasing the rival's sales (which increases the firm's price); and (iii) as the latter effect is stronger than the former one (as discussed above), the firm's price increases also with an increase in the rival's cost, although this positive marginal impact gets weaker when the products are less related.

Similarly, eq.22 shows that $\partial p_{i} / \partial u_{i}>0, \partial p_{i} / \partial u_{j}<0$ and $\left|\partial p_{i} / \partial u_{i}\right|>\left|\partial p_{i} / \partial u_{j}\right|$, $i \neq j \in\{h, f\}$, that is, (i) an increase in the firm's own product quality, or a decrease in the rival's product quality increases the firm's own price, ${ }^{14}$ and (ii) the firm's own price is more responsive to changes in its own product quality. These marginal im-

\footnotetext{
${ }^{14}$ More precisely, manufacturing higher quality has two effects (a direct demand effect and an indirect cost effect) both of which will increase prices.
} 
pacts also depend on the degree of product substitutability, such that $\partial^{2} p_{i} / \partial u_{i} \partial \sigma>0$, $\partial^{2} p_{i} / \partial u_{j} \partial \sigma<0$, and that $\left|\partial^{2} p_{i} / \partial u_{i} \partial \sigma\right|<\left|\partial^{2} p_{i} / \partial u_{j} \partial \sigma\right|, i \neq j \in\{h, f\}$, that is, (i) the marginal impacts of both the firm's own and the rival's product quality on the firm's own price get weaker when the varieties are less substitutable (when $\sigma$ is lower); and (ii) this weakening effect is greater in the case of a change in the rival's product quality. Note that (i) the firm's own price increases more with an increase in its own product quality than its own cost $\left(\partial p_{i} / \partial u_{i}>\partial p_{i} / \partial c_{i}>0, i=\{h, f\}\right)$; and (ii) the rival's product quality and cost affect the firm's own price in the same magnitude and in opposite directions (i.e., $\left|\partial p_{i} / \partial c_{j}\right|=\left|\partial p_{i} / \partial u_{j}\right|, i \neq j \in\{h, f\}$, that is, increasing the rival's cost will have the same affect on the firm's own price as decreasing the rival's quality, so long as the indirect cost effect of a change in quality is negligible.

Another important measure is a firm's markup over marginal costs, denoted $\psi_{i}=$ $\left(p_{i}^{*}-c_{i}\right) / c_{i}, i \in\{h, f\}$. While eq. (2) shows that a firm with a higher cost, or in a less competitive environment will charge a higher price, a firm's markup (i) increases with a decrease in the firm's own cost $\left(\partial \psi_{i} / \partial c_{i}<0\right)$, and this increase is even greater when the firm's product quality is higher $\left(\partial^{2} \psi_{i} / \partial c_{i} \partial u_{i}<0\right)$, or in a less competitive environment, such that when the rival has higher costs $\left(\partial^{2} \psi_{i} / \partial c_{i} \partial c_{j}<0\right)$ or lower product quality $\left(\partial^{2} \psi_{i} / \partial c_{i} \partial u_{j}>0\right)$. Similarly, a firm's markup increases also (i) with an increase in the rival's cost $\left(\partial \psi_{i} / \partial c_{j}>0\right)$ (though it is less responsive to the rival's cost than its own cost such that $\left.\left|\partial \psi_{i} / \partial c_{j}\right|<\left|\partial \psi_{i} / \partial c_{i}\right|\right)$; or (ii) with an increase in the firm's own product quality $\left(\partial \psi_{i} / \partial u_{i}>0\right)$ or with a decrease in the rival's product quality $\left(\partial \psi_{i} / \partial u_{j}<0\right)$. While a firm's markup is more responsive to changes in its own product quality than those in the rival's product quality $\left(\left|\partial \psi_{i} / \partial u_{i}\right|>\left|\partial \psi_{i} / \partial u_{j}\right|\right)$, the marginal impacts of changes in product quality (or in the rival's cost) on a firm's markup are even stronger when the degree of product substitutability is higher (as $\partial^{2} \psi_{i} / \partial u_{i} \partial \sigma>0, \partial^{2} \psi_{i} / \partial u_{j} \partial \sigma<0$, and $\left.\partial^{2} \psi_{i} / \partial c_{j} \partial \sigma>0\right)$. Moreover, all these marginal impacts and their changes are even stronger for a firm with a lower marginal cost. It should be noted in this model that $\left(p_{i}^{*}-c_{i}\right), i \in\{h, f\}$ can be interpreted in terms of price distortions over marginal costs, where $\left(p_{i}^{*}-c_{i}\right)=x_{i}^{*}, i \in\{h, f\}$ and thus the equilibrium operating profits can be expressed as $\pi_{i}^{*}=\left(x_{i}^{*}\right)^{2}$. Given these discussions, it is now clear that some of the findings reported in the related literature (as is discussed in Section 1) can easily be obtained also in this simple model, such that

Lemma 1 Firms with lower marginal costs tend to be larger in terms of sales, tend to charge lower prices and higher markups, and tend to earn higher operating profits. Increasing their product quality increases sales, prices, markups and operating profits. 
The first part of Lemma 1 holds true also for heterogeneous firm models of trade without vertical differentiation, whereas the last part is specific to those with vertical differentiation (e.g., see Manova and Zhang, 2012). As is discussed by Section 1, a similar finding is presented by several studies relying on monopolistic competition and constant elasticities and/or on heterogeneity in consumer preferences. Lemma 1 simply extends this to oligopoly in a representative consumer framework, where preferences for differentiated products are represented by a quality-augmented quadratic utility function. Different from the existing literature, however, the next section will show that upstream market power for high-quality inputs will have important implications on the input (product quality) choice of exporters and multinationals.

\section{Sourcing product quality}

Exporters and multinationals are exposed to different types of costs, which affect not only their sales but also their product quality choice by changing their input costs, especially when there is upstream market power for high-quality inputs. Similar to traditional models of trade and horizontal FDI, in this model, trade costs in final goods generate a cost disadvantage for exporters, while multinationals can avoid such costs by paying fixed investment costs and locating a subsidiary in a foreign country (e.g., see Markusen, 2002; Navaretti and Venables, 2004, and references therein). Multinationals, however, may have to bear also costs of vertical intra-industry trade, especially if they have to import certain inputs for a subsidiary in a foreign country. In this model, upstream market power for high-quality inputs renders manufacturing high quality costly both for an exporter and a multinational. In addition, given high-quality inputs are available only in $H$, a multinational has to pay per-unit input trade costs to transfer high-quality inputs to its subsidiary in $F$.

\subsection{Quality choice by a multinational}

Suppose in the first stage, firm $h$ has chosen to locate a subsidiary in $F$. In the second stage, if firm $h$ prefers to manufacture low quality by relying on inputs produced by the perfectly competitive upstream industry, then $c_{h}=c_{f}=0 ; u_{h}=u_{f}=\underline{u}$, where $\underline{u}$ represents the product quality level when low-quality inputs are used in production. 15

\footnotetext{
${ }^{15}$ Given positive input trade costs, in such a case, firm $h$ will source low-quality inputs from the perfectly competitive upstream industry located in $F$.
} 
Substituting these into equations (1) and (2), the price of firm $h$ 's variety, its sales and profits from manufacturing low quality in $F$ in equilibrium can be expressed as:

$$
p_{h}=x_{h}=\frac{\underline{u}}{2+\sigma} ; \quad \pi_{h}^{F D I}(\underline{u}, \underline{u})=\left(\frac{\underline{u}}{2+\sigma}\right)^{2}-G .
$$

It is clear from eq. (3) that an increase in $\underline{u}$, or in the degree of horizontal differentiation (such that $\sigma$ is lower), increases firm $h$ 's price, sales and profits. This case is similar to FDI models with only horizontal differentiation as there is no quality difference between the foreign and local varieties (respectively, the first and the second argument in parenthesis in the profit function, $\left.\pi_{h}^{F D I}(\cdot, \cdot)\right)$.

If, however, firm $h$ opts for a high-quality output, then the local and foreign varieties will be of different quality. In this case, given firm $h$ is a multinational, it has to transfer high-quality inputs from $H$ to its subsidiary in $F$ after having obtained inputs from the monopoly upstream firm in $H$. Thus, $c_{h}=p_{z}+t$ and $c_{f}=0 ; u_{h}=\bar{u}$ and $u_{f}=\underline{u}$, where $p_{z}$ is the input price determined by the monopoly upstream firm, $t$ is the per-unit input trade cost, and $\bar{u}$ represents the product quality level when high-quality inputs are used in production (such that $\bar{u}>\underline{u}$ ). Substituting these into eq. (1), firm $h$ 's sales $x_{h}$, given by eq.(1), can be expressed as a function of the input price. Note that highquality inputs produced by the upstream monopoly are highly customized according to the needs of the downstream multinational, whose product in $F$ shall be regarded as country specific: its product for $H$ does not affect the price of this specific input. Given $x_{h}=f(z)=z$, substituting $z$ for $x_{h}$ and re-arranging the expression, the inverse input demand can be written as $p_{z}(z)=\left(2 \bar{u}-\sigma \underline{u}-2 t-\left(4-\sigma^{2}\right) z\right) / 2$. The upstream monopoly firm maximizes its profits, $p_{z}(z) z$, by setting the optimal input price and sales as

$$
z^{*}=\frac{2 \bar{u}-\sigma \underline{u}-2 t}{2\left(4-\sigma^{2}\right)} ; \quad p_{z}=\frac{2 \bar{u}-\sigma \underline{u}-2 t}{4} .
$$

In eq. (4), $z^{*}$ also corresponds to vertical intra-industry trade. Both the high-quality input price and sales increase with a decrease in input trade costs $t$, or with an increase (decrease) in firm $h$ 's (the rival's) product quality. As might be expected, firm $h$ 's costs, $c_{h}=p_{z}+t=(2 \bar{u}-\sigma \underline{u}+2 t) / 4$, increase with an increase in $t$, with an increase in the degree of horizontal product differentiation (with a decrease in $\sigma$ ), or with an increase (decrease) in firm $h$ 's (the rival's) product quality. 
It is now straightforward to show that, in equilibrium:

$$
\begin{gathered}
p_{h}=\frac{\left(2-\sigma^{2}\right)(2 \bar{u}-\sigma \underline{u}+2 t)+4(2 \bar{u}-\sigma \underline{u})}{4\left(4-\sigma^{2}\right)} ; \quad x_{h}=\frac{2 \bar{u}-\sigma \underline{u}-2 t}{2\left(4-\sigma^{2}\right)} ; \\
\pi_{h}^{F D I}(\bar{u}, \underline{u})=\left(\frac{2 \bar{u}-\sigma \underline{u}-2 t}{2\left(4-\sigma^{2}\right)}\right)^{2}-G .
\end{gathered}
$$

Note that throughout the study, only non-prohibitive trade costs are considered such that the equilibrium prices and quantities are positive. Thus, $t<\bar{t}=\bar{u}-(\sigma \underline{u}) / 2$. Comparing prices given by equations (3) and (5), it can be shown that for any nonprohibitive $t$, a multinational charges a higher price for a high-quality product than for a low-quality product, and that the high-quality product price increases with an increase in $t$. High-quality sales, given by eq.(5), are, however, greater than low-quality sales only for sufficiently low input trade costs and for sufficiently high relative quality. ${ }^{16}$ The following result is, thus, immediate:

Proposition 1 A multinational prefers a high-quality product over a low-quality one only when $0 \leq t<((\bar{u}-\underline{u})-(\underline{u}-(\sigma \underline{u} / 2)))$, insofar as $(\bar{u} / \underline{u})>(4-\sigma) / 2$. If, however, $(\bar{u} / \underline{u})<(4-\sigma) / 2$, then for any $t<\bar{t}$, relying on low-quality inputs and engaging in low-quality subsidiary sales are more profitable than high-quality subsidiary sales for a multinational.

\section{Proof. See Appendix A.1.}

Proposition 1 shows that a sufficiently high quality difference is a necessary (but not a sufficient) condition for a multinational entering a foreign market by a high-quality product. The following remarks are in order. Decreasing $t$ decreases costs more than high-quality output prices; for a sufficiently high quality difference, both price distortions (above marginal costs) and total sales are greater when $t$ is decreased sufficiently. Input trade liberalization encourages a multinational for a high-quality output and vertical intra-industry trade in high-quality inputs only for a sufficiently high quality difference. By contrast, an increase in the degree of horizontal product differentiation (a decrease in $\sigma$ ) warrants even a higher quality difference to support manufacturing high quality by a multinational, and thus discourages quality upgrade by a multinational. The positive correlation between trade costs (distance) and quality of the traded goods reported in the literature (e.g., see Bacchiega et al., 2006) does not extend to vertical intra-industry trade in high-quality inputs by multinationals.

\footnotetext{
${ }^{16}$ Throughout the study, a sufficiently high quality difference or relative quality is referred to as the condition that $(\bar{u} / \underline{u})>(4-\sigma) / 2 \Longleftrightarrow(\bar{u}-\underline{u})-(\underline{u}-(\sigma \underline{u} / 2))>0$.
} 


\subsection{Quality choice by an exporter}

Suppose now in the first stage, firm $h$ has chosen to export its product to $F$. As in the previous section, in the second stage, if firm $h$ prefers to export low quality by relying on inputs produced by the perfectly competitive upstream industry in $H$, then $c_{h}=\tau$ and $c_{f}=0 ; u_{h}=u_{f}=\underline{u}$, where $\tau$ is the per-unit trade cost of exporting final goods. Substituting these into equations (1) and (2), the price of firm $h$ 's variety, its exports and profits from exporting low quality in $F$ in equilibrium can be expressed as:

$$
\begin{gathered}
p_{h}=\frac{\underline{u}}{2+\sigma}+\frac{\left(2-\sigma^{2}\right) \tau}{4-\sigma^{2}} ; \quad x_{h}=\frac{\underline{u}}{2+\sigma}-\frac{2 \tau}{4-\sigma^{2}} ; \\
\pi_{h}^{T}(\underline{u}, \underline{u})=\left(\frac{\underline{u}}{2+\sigma}-\frac{2 \tau}{4-\sigma^{2}}\right)^{2},
\end{gathered}
$$

where superscript $T$ stands for trade. Note that throughout the study, only nonprohibitive trade costs are considered such that the equilibrium prices and quantities are positive. Thus, $\tau<\bar{\tau}=\underline{u}-(\sigma \underline{u}) / 2$. It is clear from eq.(6) that an increase in $\underline{u}$, or in the degree of horizontal differentiation (such that $\sigma$ is lower), increases firm $h$ 's price, sales and profits. Comparing equations (3) and (6), it can be shown that also in this model, there is a tariff-jumping motive by a multinational, such that an exporter's cost disadvantage (due to trade $\operatorname{costs} \tau$ ) decreases sales and price distortions (above marginal costs) by $2 \tau /\left(4-\sigma^{2}\right)$, which is greater with a higher $\tau$ or with higher product substitutability (with higher $\sigma$ ). This case is similar to oligopolistic models of trade with only horizontal differentiation as there is no quality difference between the traded and local varieties (respectively, the first and the second argument in parenthesis in the profit function, $\left.\pi_{h}^{T}(\cdot, \cdot)\right)$.

If, however, firm $h$ opts for a high-quality output, then the local and traded varieties will be of different quality. In this case, firm $h$ is an exporter and pays trade costs in final goods, denoted $\tau$, in addition to the input price, denoted $p_{z}$, determined by the monopoly upstream firm. Thus, $c_{h}=p_{z}+\tau$ and $c_{f}=0 ; u_{h}=\bar{u}$ and $u_{f}=\underline{u}$. Substituting these into eq. (1), firm $h$ 's exports $x_{h}$, given by eq.(1), can be expressed as a function of the input price. Note that, as in the case of a downstream multinational, highquality inputs produced by the upstream monopoly are highly customized according to the needs of the downstream exporter, whose product in $F$ shall be regarded as country specific: its product for $H$ does not affect the price of this specific input. Given $x_{h}=f(z)=z$, substituting $z$ for $x_{h}$ and re-arranging the expression, the inverse input demand can be written as $p_{z}(z)=\left(2 \bar{u}-\sigma \underline{u}-2 \tau-\left(4-\sigma^{2}\right) z\right) / 2$. The upstream monopoly 
firm maximizes its profits, $p_{z}(z) z$, by setting the optimal input price and sales as

$$
z^{*}=\frac{2 \bar{u}-\sigma \underline{u}-2 \tau}{2\left(4-\sigma^{2}\right)} ; \quad p_{z}=\frac{2 \bar{u}-\sigma \underline{u}-2 \tau}{4} .
$$

In eq. (7), both the high-quality input price and sales increase with a decrease in trade costs in final goods, $\tau$, or with an increase (decrease) in firm $h$ 's (the rival's) product quality. As might be expected, firm $h$ 's costs, $c_{h}=p_{z}+\tau=(2 \bar{u}-\sigma \underline{u}+2 \tau) / 4$, increases with an increase in $\tau$, with an increase in the degree of horizontal product differentiation (with a decrease in $\sigma$ ), or with an increase (decrease) in firm $h$ 's (the rival's) product quality.

It is now straightforward to show that, in equilibrium:

$$
\begin{gathered}
p_{h}=\frac{\left(2-\sigma^{2}\right)(2 \bar{u}-\sigma \underline{u}+2 \tau)+4(2 \bar{u}-\sigma \underline{u})}{4\left(4-\sigma^{2}\right)} ; \quad x_{h}=\frac{2 \bar{u}-\sigma \underline{u}-2 \tau}{2\left(4-\sigma^{2}\right)} ; \\
\pi_{h}^{T}(\bar{u}, \underline{u})=\left(\frac{2 \bar{u}-\sigma \underline{u}-2 \tau}{2\left(4-\sigma^{2}\right)}\right)^{2} .
\end{gathered}
$$

Notice that in this model, the difference between an exporter and a multinational producing a high-quality product is mainly determined by differences in product-specific trade costs. Comparing equations (5) and (8), it can easily be shown that

Proposition 2 Variation in input prices, sales and price distortions (above marginal costs) between an exporter and a multinational results from differences in productspecific trade costs (i.e., input trade costs vs. trade costs in final goods). If $\tau>t$, then (compared to a multinational sourcing high-quality inputs from a monopoly supplier in $H$ ), an exporter of a high-quality product

- demands less inputs from the monopoly supplier in $H$, and pays $(\tau-t) / 2$ less,

- distorts prices (above marginal costs) less and decreases sales by $(\tau-t) /\left(4-\sigma^{2}\right)$.

The greater the difference between trade costs in inputs and in final goods, the greater these decreases. Given such a cost disadvantage of the exporter, its price distortions and sales decrease even more if the traded and local varieties are more substitutable (higher $\sigma$ ), although for any $\sigma \in(0,1)$, these decreases are less than those in input prices paid by the exporter. 
Also, comparing prices given by equations (6) and (8), it can be shown that for any non-prohibitive $\tau$ (such that $\tau<\bar{\tau}$ ), an exporter charges a higher price for a highquality product than for a low-quality product. Both the high-quality and the lowquality product price increase with an increase in $\tau$, although the low-quality product price increases twice as much as the increase in the high-quality product price due to double marginalization in the high-quality product price. This implies that the difference between the high-quality and the low-quality product price decreases with an increase in trade costs. Moreover, high-quality exports, given by eq.(8), are greater than low-quality exports for any $\tau<\bar{\tau}$ so long as there is sufficiently high relative quality. If, however, the quality difference between the local and traded varieties is small, then only for a sufficiently high trade cost, high-quality exports are greater than low-quality exports. The following result is, thus, immediate:

Proposition 3 An exporter prefers a high-quality product over a low-quality one for any $\tau<\bar{\tau}$ insofar as $(\bar{u} / \underline{u})>(4-\sigma) / 2$. If, however, $(\bar{u} / \underline{u})<(4-\sigma) / 2$, then relying on high-quality inputs and exporting high quality is more profitable than exporting low quality only when $(\underline{u}-(\sigma \underline{u} / 2)-(\bar{u}-\underline{u}))<\tau<\bar{\tau}$.

\section{Proof. See Appendix A.2.}

Proposition 3 shows that a sufficiently high quality difference is not necessary, though is sufficient for an exporter selling a high-quality product in a foreign market. The following remarks are in order. Decreasing $\tau$ decreases costs more than high-quality output prices; for a sufficiently high quality difference, or for a small quality difference and sufficiently high $\tau$, both price distortions (above marginal costs) and total sales are greater. Trade liberalization in final goods does not contribute much to an exporter's incentives to produce a high-quality output; it may even discourage an exporter to produce a high-quality product, especially when relative quality is sufficiently low. The reason is that an exporter's input demand will increase with a decrease in trade costs, which will lead the upstream monopoly to increase the input price. When relative quality and trade costs are both sufficiently low, the benefit from a costly quality upgrade falls short of the increase in the exporter's costs due to double marginalization. If, however, trade costs in final goods are sufficiently high, and thus an exporter's input demand and sales will be sufficiently small, it will pay off for the exporter to upgrade quality as the costs will not be that high. By the same token, the positive correlation between trade costs (distance) and product quality reported in the literature (e.g., see Bacchiega et al., 2006) is confirmed only when relative quality is sufficiently low. 
It is now clear from Propositions (1)-(3) that

Proposition 4 A higher degree of horizontal product differentiation can undermine a firm's effort of costly quality upgrading, irrespective of the foreign market entry mode.

As in the case of a multinational discussed in the previous section, also for an exporter, an increase in the degree of horizontal product differentiation (a decrease in $\sigma$ ) is pitted against quality upgrading. A higher degree of horizontal product differentiation warrants even a higher quality difference to support exporting high quality, and thus can discourage quality upgrading also by an exporter, especially if trade costs in final goods are also sufficiently low. Proposition 4 implies that vertical and horizontal product differentiation are, to some extent, substitute activities. When local and foreign varieties are more substitutable, competition will be more intense encouraging firms to differentiate product quality so as to decrease competition intensity. An empirical prediction that follows Proposition 4 is that quality differentiation among products might be prevalent in industries with a higher degree of product substitutability among product varieties.

\section{Foreign market entry}

This section scrutinizes the equilibrium foreign market entry mode of firm $h$, which is determined in the first stage. It is now clear from the above discussions that relative product quality, product substitutability, and product-specific trade costs play a crucial role in firm-level decisions. This section, thus, distinguishes between two cases: high vs. low relative product quality of the foreign variety.

\subsection{High relative product quality}

Suppose that higher-quality inputs provided by the monopoly upstream firm are such that the quality difference between the local and foreign varieties is sufficiently high: $(\bar{u} / \underline{u})>(4-\sigma) / 2$. Proposition 1 has already shown that in such a case, a multinational prefers high-quality subsidiary sales only for sufficiently low input trade costs, such that $\pi_{h}^{F D I}(\bar{u}, \cdot)>\pi_{h}^{F D I}(\underline{u}, \cdot)$ if $t<((\bar{u}-\underline{u})-(\underline{u}-(\sigma \underline{u} / 2))){ }^{17}$ By contrast, Proposition 3

\footnotetext{
${ }^{17}$ Note that the second argument that is represented by a center-dot $(\cdot)$ in the profit function is simply the local variety's product quality $(\underline{u})$.
} 
has shown that in such a case, an exporter prefers to produce and sell a high-quality product over a low-quality one for any non-prohibitive trade costs in final goods, such that $\pi_{h}^{T}(\bar{u}, \cdot)>\pi_{h}^{T}(\underline{u}, \cdot)$ for any $\tau<\bar{\tau}$. Thus firm $h$ has to compare $\pi_{h}^{F D I}(\bar{u}, \cdot)$ and $\pi_{h}^{T}(\bar{u}, \cdot)$ for low values of input trade costs (to the left of the vertical line depicted at $t=((\bar{u}-\underline{u})-(\underline{u}-(\sigma \underline{u} / 2)))$ in Figures 1 and 2$)$, while comparing $\pi_{h}^{F D I}(\underline{u}, \cdot)$ and $\pi_{h}^{T}(\bar{u}, \cdot)$ for high values of input trade costs (to the right of the vertical line depicted at $t=$ $((\bar{u}-\underline{u})-(\underline{u}-(\sigma \underline{u} / 2)))$ in Figures 1 and 2$) \cdot{ }^{18}$ To illustrate the results, both Figures 1 and 2 confine the relevant area such that trade costs are non-prohibitive, that is, the area below the dashed-line $\bar{\tau}=\underline{u}-(\sigma \underline{u} / 2)$ and to the left of the dashed-line $\bar{t}=\bar{u}-(\sigma \underline{u} / 2)$. Note that in Figure 1, although there is high relative quality, it is not substantial such that $(4-\sigma) / 2<\bar{u} / \underline{u}<(3-\sigma)$, and thus $\bar{\tau}=\underline{u}-(\sigma \underline{u} / 2)>((\bar{u}-\underline{u})-(\underline{u}-(\sigma \underline{u} / 2)))$. By contrast, Figure 2 illustrates the cases where relative quality is substantially high such that $\bar{u} / \underline{u}>(3-\sigma)$. Thus, in Figure $2, \bar{\tau}=\underline{u}-(\sigma \underline{u} / 2)<((\bar{u}-\underline{u})-(\underline{u}-(\sigma \underline{u} / 2)))$ which implies that any non-prohibitive trade cost in final goods will already be below the horizontal line depicted at $\tau=((\bar{u}-\underline{u})-(\underline{u}-(\sigma \underline{u} / 2)))$.

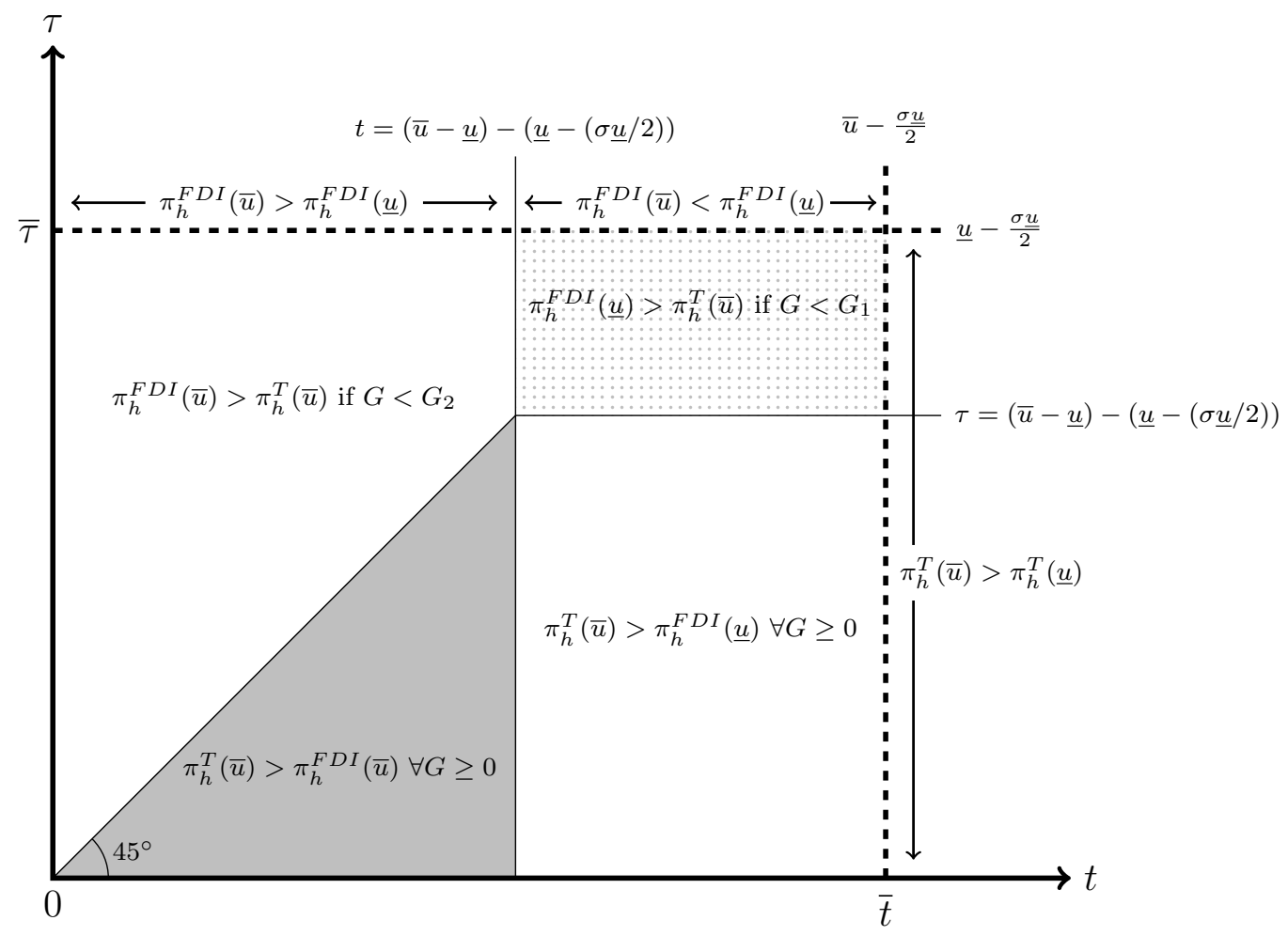

Figure 1: Relative product quality: $(4-\sigma) / 2<\bar{u} / \underline{u}<(3-\sigma)$

\footnotetext{
${ }^{18}$ In all Figures, the second argument in the profit function, which represents the local variety's product quality is omitted, and only firm $h$ 's product quality is registered.
} 


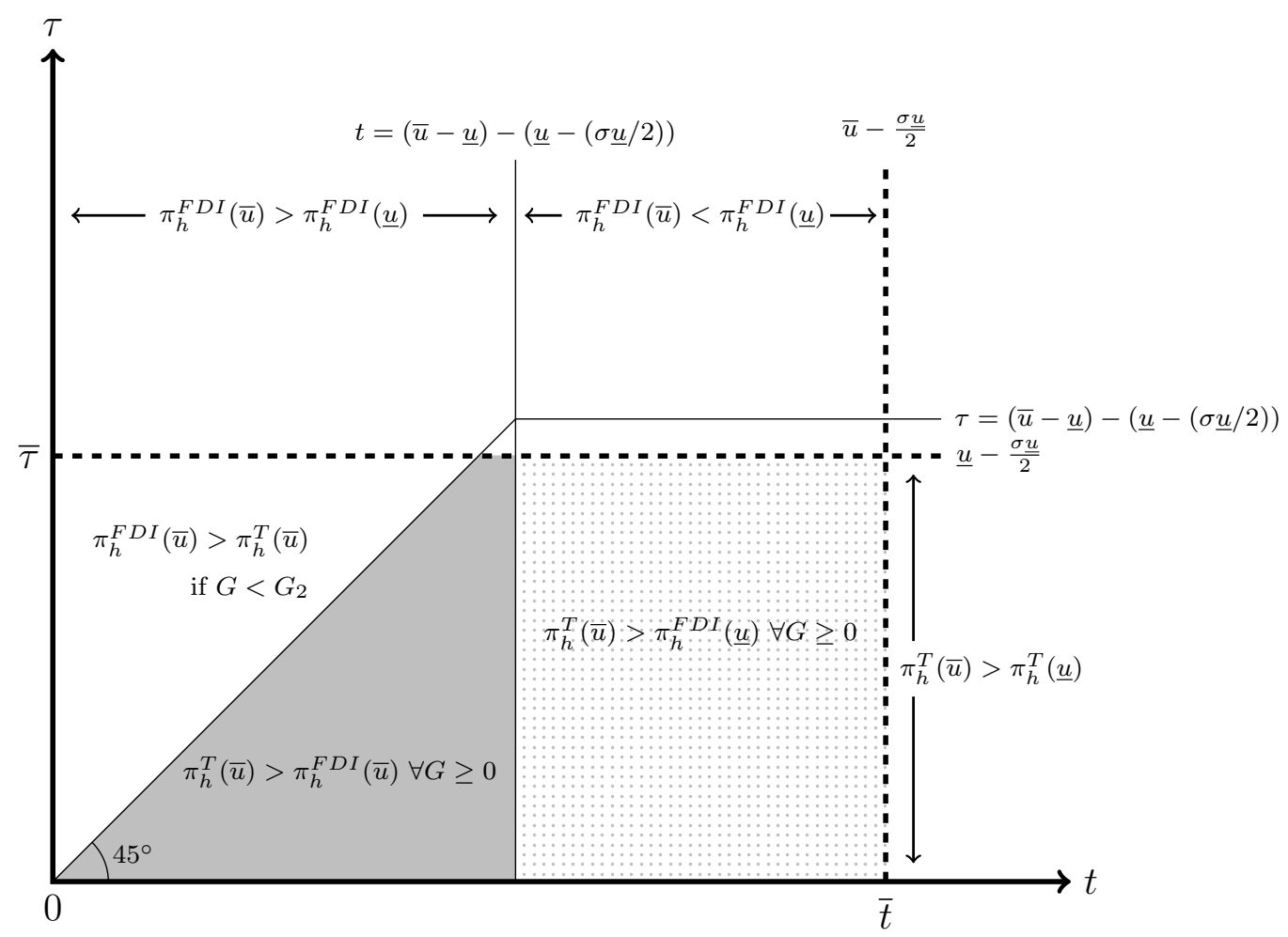

Figure 2: Relative product quality: $\bar{u} / \underline{u}>(3-\sigma)$

It is clear that low-quality subsidiary sales can emerge as the equilibrium outcome when relative quality is high, but not substantial (see the hatched area - the upper right corner - in Figure 1). In such a case, low-quality subsidiary sales are supported in equilibrium, especially if both trade costs in inputs and final goods are sufficiently high, and fixed investment costs are sufficiently low, such that $G<G_{1}$. If, however, relative quality is substantial, as is illustrated by Figure 2 , such that $\bar{u} / \underline{u}>(3-\sigma)$, in equilibrium, manufacturing high quality will be optimal for both multinationals and exporters. In such a case, high-quality exports dominate subsidiary sales of any quality so long as trade costs in final goods are below those in inputs, such that $\tau<t$. That said, high-quality subsidiary sales can also emerge as the equilibrium outcome, especially if input trade costs are below trade costs in final goods (the area above the 45-degree line where $\tau>t$ ), and if fixed investment costs are sufficiently low, such that $G<G_{2}$. These results hold true also for the case that relative product quality is high (but not substantial) as is illustrated by Figure 1 , such that $(4-\sigma) / 2<\bar{u} / \underline{u}<(3-\sigma)$, although they hold true only for certain values of input trade costs. In particular, the case that $\tau>t$ holds is likely, especially if trade costs are interpreted as physical (transportation) costs; e.g., transporting a final good, such as a car, will be more costly than transporting 
only inputs, such as the engine or seats of the car. Proposition 5 summarizes the findings for all possible equilibrium foreign market entry modes depending on different constellations of parameter values of $t$ and $\tau$, such that

Proposition 5 When relative quality is sufficiently high such that $(\bar{u} / \underline{u})>(4-\sigma) / 2$, in equilibrium,

- for sufficiently high trade costs in both inputs and final goods, such that $(t, \tau)>>$ $((\bar{u}-\underline{u})-(\underline{u}-(\sigma \underline{u} / 2)))$, low-quality subsidiary sales are optimal if fixed investment costs are sufficiently low, such that $G<G_{1}$ (or high-quality exports if $G>G_{1}$ );

- given sufficiently high input trade costs, if trade costs in final goods decrease sufficiently such that $\tau<((\bar{u}-\underline{u})-(\underline{u}-(\sigma \underline{u} / 2)))<t$, then exporting a highquality variety is optimal, irrespective of fixed investment costs;

- if both trade costs decrease sufficiently, while those in final goods decrease faster, such that $\tau<t<((\bar{u}-\underline{u})-(\underline{u}-(\sigma \underline{u} / 2)))$, although a multinational would upgrade quality, exporting high quality is optimal, irrespective of fixed investment costs;

- given sufficiently low input trade costs, if trade costs in final goods are higher (if $t<((\bar{u}-\underline{u})-(\underline{u}-(\sigma \underline{u} / 2)))$ and $\tau>t)$, then high-quality subsidiary sales are optimal if fixed investment costs are sufficiently low, such that $G<G_{2}$ (or high-quality exports if $G>G_{2}$ ).

Proof. See Figures 1 and 2 , and Appendix A.3.

Note that for the first bullet point in Proposition 5. Appendix A.3 shows that in the relevant range of trade costs, such that $(t, \tau)>>((\bar{u}-\underline{u})-(\underline{u}-(\sigma \underline{u} / 2)))$, threshold fixed investment cost $G_{1}$ increases with trade costs in final goods, $\tau$. Assuming that relative quality is not substantial, such that $(4-\sigma) / 2<\bar{u} / \underline{u}<(3-\sigma)$, the higher the non-prohibitive trade costs in final goods, the higher the fixed investment cost threshold, below which low-quality subsidiary sales are supported in equilibrium. That is, in the hatched area in Figure 1 (the upper right corner), as trade costs in final goods increase further, the probability of low-quality subsidiary sales increases. Similarly, as for the last bullet point in Proposition 5. Appendix A.3 shows that in the relevant range of trade costs, such that $\tau>t$ (the area above the 45-degree line in both Figures 1 and 2), the higher the trade costs in final goods above input trade costs - the higher is $(\tau-t)$ - the higher the fixed investment cost threshold, below which high-quality 
subsidiary sales are preferred over high-quality exports. In particular, threshold fixed investment cost $G_{2}$ increases with a decrease in input trade costs $t$, whereas it increases with an increase in trade costs in final goods, $\tau$. Thus the probability of high-quality subsidiary sales increases as the difference between trade costs in final goods and those in inputs increases further.

It is immediate from Proposition 5 that when relative quality is high, trade liberalization in final goods (decreasing $\tau$ ) can promote high-quality exports against low-quality subsidiary sales even for zero fixed investment costs. This holds true also against highquality subsidiary sales: while input trade liberalization can lead to quality upgrading by a multinational, if trade costs in final goods decrease faster than those in inputs, then high-quality exports are preferred also over high-quality subsidiary sales, even for zero fixed investment costs. In particular, these results stand in stark contrast to FDI models without vertical product differentiation, where FDI emerges as the equilibrium foreign market entry mode under zero fixed investment costs and positive trade costs. If, however, input trade costs decrease faster than those in final goods, then high-quality vertical intra-industry trade and high-quality subsidiary sales can be promoted against high-quality exports so long as relative quality is high and fixed investment costs are sufficiently low. Therefore, consistent with the trade literature discussed in Section 1 , also in this model, asymmetric product-specific trade liberalization has some important implications on firm-level decisions.

\subsection{Low relative product quality}

Suppose now that higher-quality inputs provided by the monopoly upstream firm are such that the quality difference between the local and foreign varieties is sufficiently low: $(\bar{u} / \underline{u})<(4-\sigma) / 2$. Proposition 1 has already shown that in such a case, a multinational prefers manufacturing low quality in $F$ for any non-prohibitive input trade costs, such that $\pi_{h}^{F D I}(\underline{u})>\pi_{h}^{F D I}(\bar{u})$ for any $t<\bar{t}$. By contrast, Proposition 3 has shown that in such a case, an exporter prefers to produce and sell a high-quality product over a lowquality one only for sufficiently high trade costs in final goods, such that $\pi_{h}^{T}(\bar{u})>\pi_{h}^{T}(\underline{u})$ if $((\underline{u}-(\sigma \underline{u} / 2))-(\bar{u}-\underline{u}))<\tau<\bar{\tau}$. Thus, in such a case, firm $h$ has to compare $\pi_{h}^{F D I}(\underline{u})$ and $\pi_{h}^{T}(\underline{u})$ for low values of trade costs in final goods (below the horizontal line depicted at $\tau=((\underline{u}-(\sigma \underline{u} / 2))-(\bar{u}-\underline{u}))$ in Figure 3), while comparing $\pi_{h}^{F D I}(\underline{u})$ and $\pi_{h}^{T}(\bar{u})$ for high values of trade costs in final goods (above the horizontal line depicted at $\tau=((\underline{u}-(\sigma \underline{u} / 2))-(\bar{u}-\underline{u}))$ in Figure 3). As in Figures 1 and 2 , to illustrate the results, Figure 3 confines the relevant area such that trade costs are non-prohibitive. Given that 
$\bar{u} / \underline{u}<(4-\sigma) / 2$, in this case (different from the cases above), $\bar{\tau}>((\underline{u}-(\sigma \underline{u} / 2))-(\bar{u}-\underline{u}))$ always holds.

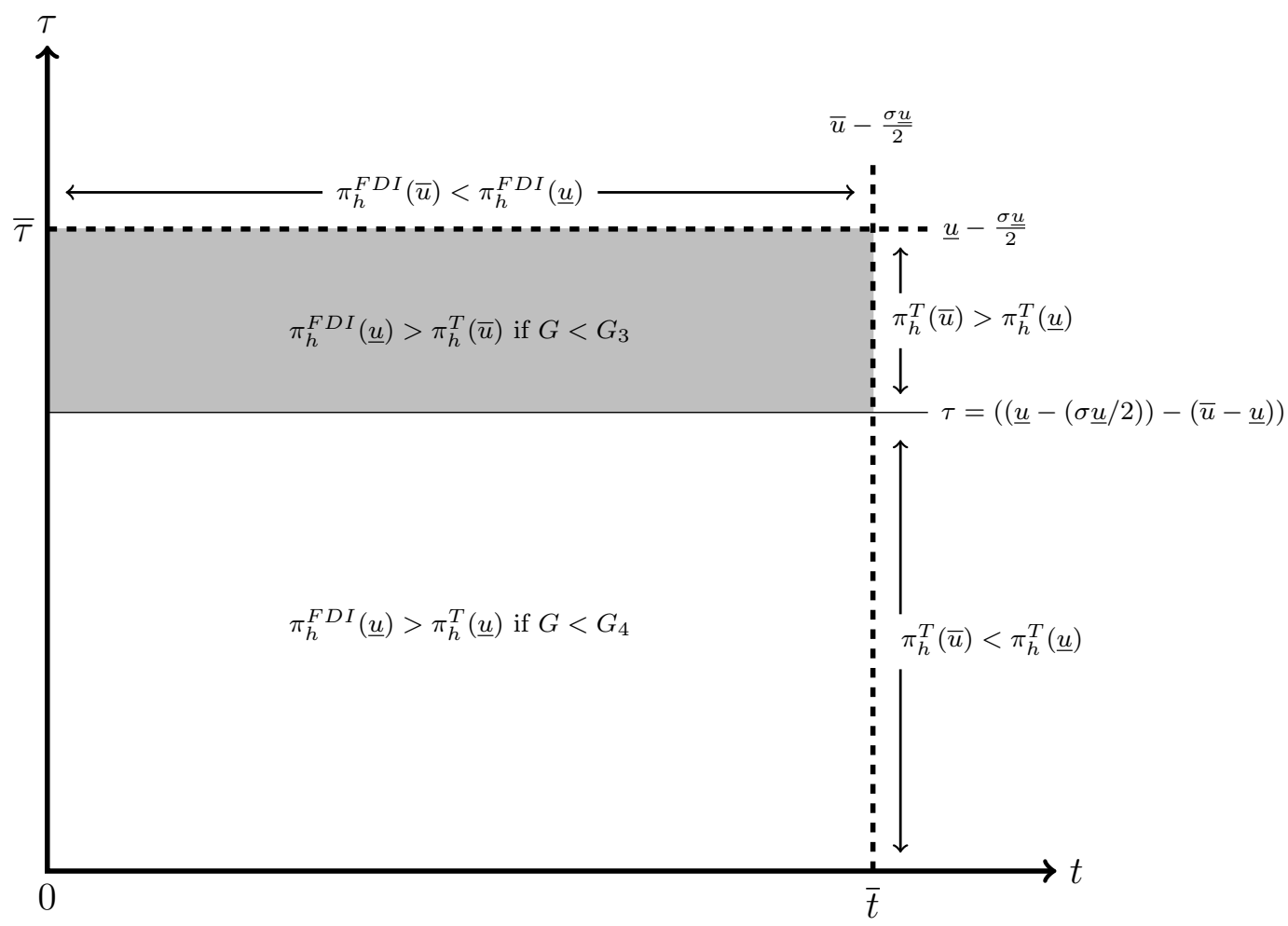

Figure 3: Relative product quality: $\bar{u} / \underline{u}<(4-\sigma) / 2$

Figure 3 clearly shows that when relative product quality is low, such that $\bar{u} / \underline{u}<$ $(4-\sigma) / 2$, trade costs in final goods and fixed investment costs mainly determine the equilibrium outcome, as in the standard FDI literature. For sufficiently high trade costs in final goods, low-quality subsidiary sales are supported in equilibrium, especially if fixed investment costs are sufficiently low, such that $G<G_{3}$. Note that as is shown by Appendix A.4, threshold fixed investment cost $G_{3}$ increases with an increase in trade costs in final goods, $\tau$. Thus, an increase in trade costs in final goods in the shaded area in Figure 3 (the upper rectangle) increases the probability of low-quality subsidiary sales. Similarly, for sufficiently low trade costs in final goods, low-quality subsidiary sales are also supported in equilibrium, especially if fixed investment costs are sufficiently low, such that $G<G_{4}$. Appendix A.4 shows that threshold fixed investment cost $G_{4}$ also increases with an increase in trade costs in final goods, $\tau$. Thus, although an increase in trade costs in final goods encourages an exporter to upgrade quality when relative quality is sufficiently low, the probability of low-quality subsidiary sales increases with such an increase (as both $G_{3}$ and $G_{4}$ are positively related to $\tau$ ). 
Proposition 6 summarizes all possible equilibrium foreign market entry modes depending on different constellations of parameter values of $t$ and $\tau$, such that

Proposition 6 When relative quality is sufficiently low such that $(\bar{u} / \underline{u})<(4-\sigma) / 2$, in equilibrium,

- for sufficiently high trade costs in final goods, $(\underline{u}-(\sigma \underline{u} / 2)-(\bar{u}-\underline{u}))<\tau<\bar{\tau}$, low-quality subsidiary sales are optimal for sufficiently low fixed investment costs, such that $G<G_{3}$ (or high-quality exports if $G>G_{3}$ );

- for sufficiently low trade costs in final goods, such that $\tau<(\underline{u}-(\sigma \underline{u} / 2)-(\bar{u}-\underline{u}))$, low-quality subsidiary sales are optimal for sufficiently low fixed investment costs, such that $G<G_{4}$ (or low-quality exports if $G>G_{4}$ ).

Proof. See Figure 3 and Appendix A.4.

It is immediate from Proposition 6 that when relative quality and fixed investment costs are sufficiently low, decreasing trade costs in final goods only leads to quality downgrading by an exporter, while low-quality subsidiary sales dominate irrespective of input trade costs (so long as they are non-prohibitive).

\section{Vertical integration}

In this section, the model is extended to vertical integration so as to flash out the role upstream market power plays in the optimal foreign market entry mode and product quality. In the case of vertical integration, there is no double marginalization, and highquality inputs can be procured at zero marginal cost (from the integrated upstream firm). If the integrated firm has chosen to locate a subsidiary in $F$, then it pays input trade costs $t$ to transfer high-quality inputs from $H$ to its subsidiary in $F$ so as to manufacture high quality in $F$. Thus $c_{h}=t, c_{f}=0$, and $u_{h}=\bar{u}, u_{f}=\underline{u}$. Substituting these into equations (1) and (2), the price of high-quality foreign variety, the integrated firm's sales and profits in $F$ in equilibrium can be expressed as:

$$
\begin{gathered}
p_{h}^{v}=\frac{2 \bar{u}-\sigma \underline{u}+\left(2-\sigma^{2}\right) t}{4-\sigma^{2}} ; \quad x_{h}^{v}=\frac{2 \bar{u}-\sigma \underline{u}-2 t}{4-\sigma^{2}} ; \\
\pi_{h}^{v, F D I}(\bar{u}, \underline{u})=\left(\frac{2 \bar{u}-\sigma \underline{u}-2 t}{4-\sigma^{2}}\right)^{2}-G,
\end{gathered}
$$


where superscript $v$ stands for the case of vertical integration.

If, however, the integrated firm has chosen to manufacture in $H$ and to export highquality final goods to $F$, then it pays $\tau$ to export final goods from $H$ to $F$. Thus $c_{h}=\tau$, $c_{f}=0$, and $u_{h}=\bar{u}, u_{f}=\underline{u}$. Substituting these into equations (1) and (2), the price of high-quality foreign variety, the integrated firm's sales and profits in $F$ in equilibrium can be expressed as:

$$
\begin{gathered}
p_{h}^{v}=\frac{2 \bar{u}-\sigma \underline{u}+\left(2-\sigma^{2}\right) \tau}{4-\sigma^{2}} ; \quad x_{h}^{v}=\frac{2 \bar{u}-\sigma \underline{u}-2 \tau}{4-\sigma^{2}} ; \\
\pi_{h}^{v, T}(\bar{u}, \underline{u})=\left(\frac{2 \bar{u}-\sigma \underline{u}-2 \tau}{4-\sigma^{2}}\right)^{2},
\end{gathered}
$$

Comparing eq.(9) with eq.(5), and eq.(10) with eq.(8) reveals that, as might be expected, irrespective of the foreign market entry mode, vertical integration between the monopoly upstream and the downstream firm increases (doubles) the foreign firm's sales and decreases its price. That said, vertical integration leads to higher price distortions around marginal costs as the decrease in the high-quality input price is greater than the decrease in the final goods price ${ }^{19}$ Also, as might be expected, vertical integration can be mutually beneficial as the joint firm profits under vertical integration are greater than the sum of independent firm profits under upstream market power. ${ }^{20}$

Comparing profits given by eq.(9) and eq.(3) shows that for a vertically integrated multinational, manufacturing a high-quality product in $F$ is more profitable than opting for a low-quality product, so long as, for any given relative quality, input trade costs are less than the quality difference between the foreign and the local variety (i.e., $t<\bar{u}-\underline{u})$. It is straightforward to introduce variable or fixed costs specific to vertical integration such that in the case of variable costs, input trade costs should be replaced by $c_{h}=c+t$ in $\pi_{h}^{v, F D I}(\bar{u}, \underline{u})$ given by eq.(9), or in the case of fixed costs, $\bar{C}$ can be

\footnotetext{
${ }^{19} \mathrm{~A}$ similar exercise can be carried out for the local firm, in which case, it is straightforward to show that vertical integration between the monopoly upstream and the downstream foreign firm (i) decreases local sales; (ii) increases the price of the low-quality local variety; (iii) increases aggregate sales in $F$ (as the increase in the sales of the high-quality foreign variety is greater than the decrease in the low-quality local variety); and (iv) decreases local profits.

${ }^{20}$ It should be noted that the individual benefits from vertical integration depend on each firm's bargaining power and on each firm's disagreement profits (threat points), especially if generalized Nash bargaining is employed to determine how the firms share the gains from vertical integration. That said, replacing upstream market power by bargaining power, however, generates qualitatively the same results as in Sections 3 and 4 (computations are available upon request). Thus, to better highlight the role of upstream market power in a foreign firm's product quality and market entry mode choice, in this section, only the integrated firm is considered.
} 
included in (subtracted from) $\pi_{h}^{v, F D I}(\bar{u}, \underline{u})$ given by eq.(9). Comparing those and eq.(3) then leads to the following result.

Proposition 7 A multinational tends to opt for quality upgrade via vertical integration (i) if the quality difference between the local and the foreign varieties is large enough to cover input trade costs (i.e., $t<\bar{u}-\underline{u}$ ); or (ii) if the integrated multinational has sufficiently low marginal costs $c<\bar{u}-\underline{u}-t$ (when vertical integration warrants additional variable costs); or (iii) if the integrated firm has sufficiently low fixed costs along with low input trade costs and variable costs, especially when vertical integration warrants also additional fixed costs.

\section{Proof. See Appendix A.5.}

It is now clear from Propositions 1 and 7 that avoiding double marginalization (due to upstream market power) by vertical integration enables the integrated multinational to manufacture high quality also for low relative quality and for higher input trade costs. Moreover, Proposition 7 suggests that there may be sorting for product quality such that more productive multinationals may opt for higher quality products in countries where input trade costs are sufficiently low. Or to put it differently, more productive multinationals can handle higher input trade costs when upgrading product quality, which is consistent with the findings of the related literature. In contrast to a multinational, comparing eq. 10) and eq.(6) shows that a vertically integrated exporter's profits are greater with a high-quality product than with a low-quality product, irrespective of (non-prohibitive) trade costs or relative product quality. As in the case of a multinational, also for an exporter, it is straightforward to introduce variable and/or fixed costs specific to vertical integration such that in the case of variable costs, trade costs in final goods in $\pi_{h}^{v, T}(\bar{u}, \underline{u})$ given by eq. 10 should be replaced by $c_{h}=c+\tau$, or in the case of fixed costs, $\bar{C}$ can be included in (subtracted from) $\pi_{h}^{v, T}(\bar{u}, \underline{u})$ given by eq. (10). Comparing those and eq. (6) then leads to the following result.

Proposition 8 An exporter tends to opt for quality upgrade via vertical integration for any given (non-prohibitive) trade costs in final goods insofar as the quality difference between the local and the foreign varieties is large enough to cover variable costs that might have arisen due to vertical integration (i.e., $c<\bar{u}-\underline{u}$ ) and/or fixed costs resulting from vertical integration are sufficiently low.

Proof. See Appendix A.6. 
While the integrated exporter's behavior is the same as in the case of upstream market power, especially when relative quality is sufficiently high (see the first part of Proposition 3), avoiding double marginalization enables the integrated exporter to manufacture high quality also for a low quality difference, irrespective of trade costs in final goods. Moreover, similar to Proposition 7, Proposition 8 suggests that there may be sorting for product quality also for an exporter such that more productive exporters may opt for higher quality products. Also comparing equations (9) and (10) shows that, as in the case of no vertical integration but upstream market power,

Proposition 9 Variation in input prices, sales and price distortions (above marginal costs) between an integrated exporter and an integrated multinational results from differences in product-specific trade costs (i.e., input trade costs vs. trade costs in final goods). If $\tau>t$, then (compared to an integrated multinational manufacturing high quality), an integrated exporter of a high-quality product distorts prices (above marginal costs) less and decreases sales by $2(\tau-t) /\left(4-\sigma^{2}\right)$ (double the decrease compared to the case of no vertical integration). This decrease is greater the greater is the difference between trade costs in inputs and in final goods, or the lower is the degree of product differentiation (the higher is $\sigma$ ).

When is quality upgrading through vertical integration optimal in equilibrium? Given the results in Propositions 7 and 8 , to decide on the equilibrium firm behavior: (i) when input trade costs are sufficiently low such that $t<(\bar{u}-\underline{u})$, a potential (integrated) multinational's optimal behavior (that is to vertically integrate and manufacture high quality) and profits $\left(\pi_{h}^{v, F D I}(\bar{u}, \underline{u})\right.$ given by eq. $\left.(9)\right)$ should be compared with a potential (integrated) exporter's optimal behavior (that is to vertically integrate and manufacture high quality) and profits $\left(\pi_{h}^{v, T}(\bar{u}, \underline{u})\right.$ given by eq. $(10)$ ); and (ii) when input trade costs are sufficiently high such that $t>(\bar{u}-\underline{u})$, a potential (integrated) multinational's optimal behavior (that is to rely on low-quality inputs and manufacture low quality) and profits $\left(\pi_{h}^{F D I}(\underline{u}, \underline{u})\right.$ given by eq. $\left.3 p\right)$ should be compared with a potential (integrated) exporter's optimal behavior (that is to vertically integrate and manufacture high quality) and profits $\left(\pi_{h}^{v, T}(\bar{u}, \underline{u})\right.$ given by eq. 10$)$. This leads to

Proposition 10 The equilibrium firm behavior is such that

- When $t>\bar{u}-\underline{u}$, exporting high quality is optimal for any fixed investment costs $G \geq 0$ if (and only if) $\tau<\bar{u}-\underline{u}$. If, however, also $\tau>\bar{u}-\underline{u}$, then exporting 
through vertical integration is optimal (compared to low-quality subsidiary sales) only for sufficiently high fixed investment costs $G>G_{5}$.

- When $t<\bar{u}-\underline{u}$, manufacturing high quality through vertical integration is optimal and the integrated firm prefers exporting over FDI for any fixed investment costs $G \geq 0$ so long as $\tau<t$. If, however, $\tau>t$, then the integrated firm prefers exporting over FDI only for sufficiently high fixed investment costs $G>G_{6}$.

\section{Proof. See Appendix A.7.}

Also in this case, relative quality of the foreign variety is important for the equilibrium firm outcome as is illustrated by Figure 4 (where relative quality is sufficiently but not substantially high such that $(4-\sigma) / 2<\bar{u} / \underline{u}<(3-\sigma)$ ), by Figure 5 (where relative quality is substantially high such that $\bar{u} / \underline{u}>(3-\sigma)$ ), and by Figure 6 (where relative quality is sufficiently low such that $(4-\sigma) / 2>\bar{u} / \underline{u})$. As in the previous section, in all figures in this section, only non-prohibitive trade costs are illustrated such that $t<\bar{t}=\bar{u}-\sigma \underline{u} / 2$ and $\tau<\bar{\tau}=\underline{u}-\sigma \underline{u} / 2$.

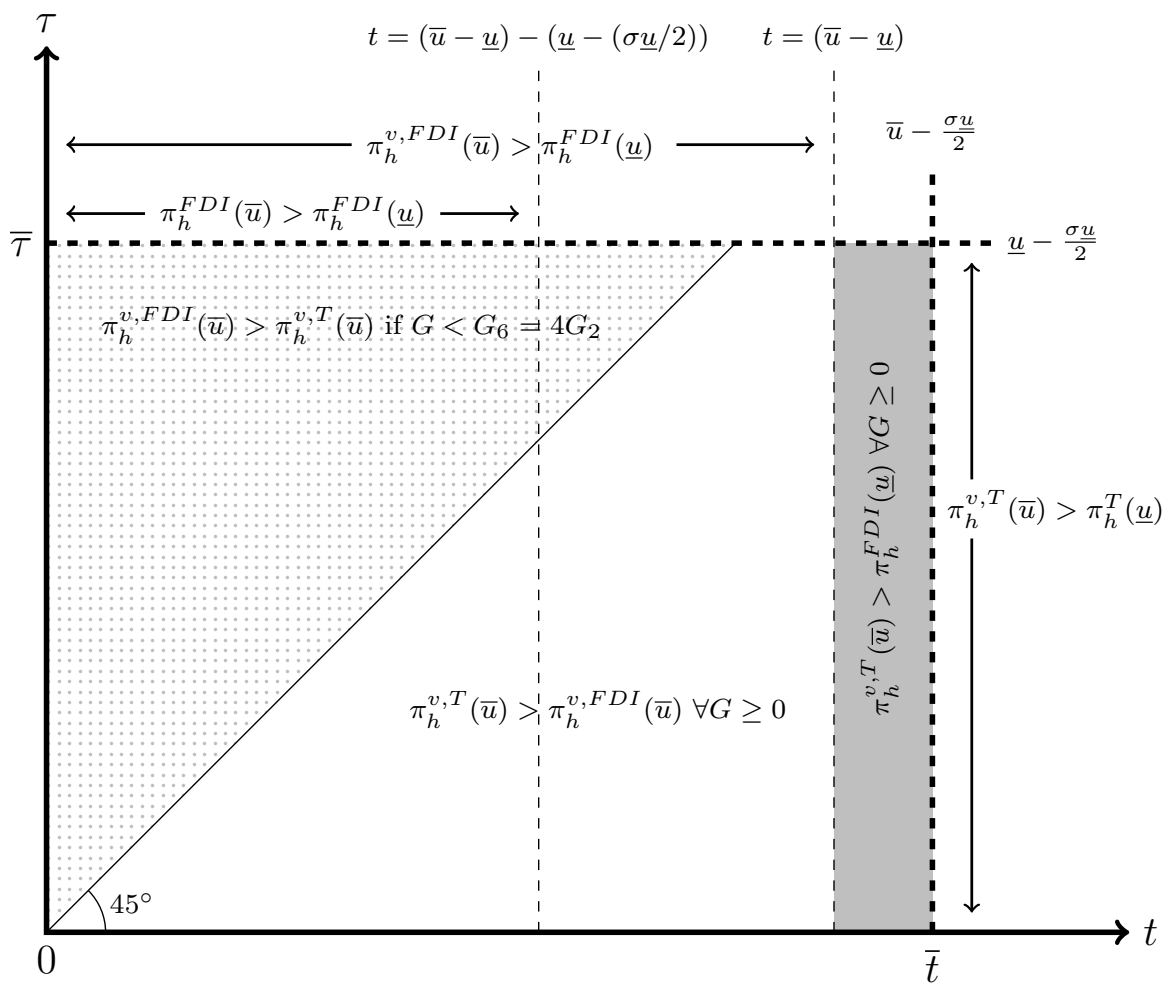

Figure 4: Vertical integration; Relative product quality: $(4-\sigma) / 2<\bar{u} / \underline{u}<(3-\sigma)$

When relative quality is high such that $(\bar{u}-\underline{u})>(\underline{u}-(\sigma \underline{u} / 2))$, any non-prohibitive trade cost in final goods $(\tau<\bar{\tau}=\underline{u}-\sigma \underline{u} / 2)$ should be always less than the quality 


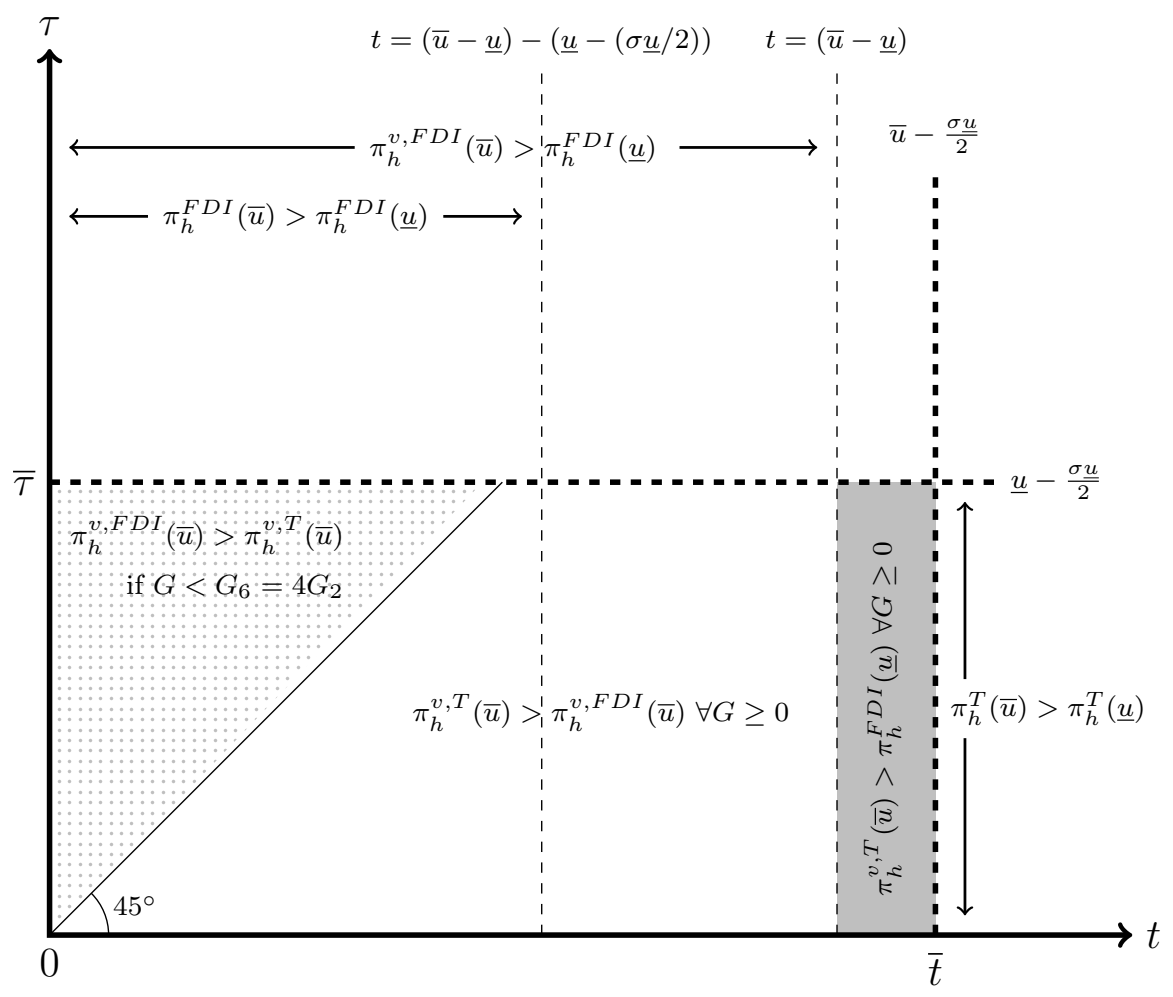

Figure 5: Vertical integration; Relative product quality: $\bar{u} / \underline{u}>(3-\sigma)$

difference between the two varieties such that $\tau<(\bar{u}-\underline{u})$. Thus, as is given by the first bullet point in Proposition 10, when $t>(\bar{u}-\underline{u})$, in equilibrium, the integrated firm prefers exporting its high-quality variety over subsidiary sales, even for zero fixed investment costs. The reason is simply high input trade costs. While decreasing input trade costs encourages a multinational to upgrade the quality of its variety, high-quality subsidiary sales through vertical integration will emerge as the equilibrium outcome only for sufficiently low input trade costs (such that $t<\tau$ ) and for sufficiently low fixed investment costs (such that $G<G_{6}$ ). As in the case of upstream market power, under vertical integration, the higher the trade costs in final goods above input trade costs the higher is $(\tau-t)$ - the higher the fixed investment cost threshold, below which highquality subsidiary sales are preferred over high-quality exports. In particular, threshold fixed investment cost $G_{6}$ increases with a decrease in input trade costs $t$, whereas it increases with an increase in trade costs in final goods, $\tau$ (see Appendix A.7). Thus the probability of high-quality subsidiary sales increases as the difference between trade costs in final goods and those in inputs increases further.

Figures 4 and 5 clearly show that when relative quality is sufficiently high, avoiding double marginalization by vertical integration and manufacturing high quality are op- 


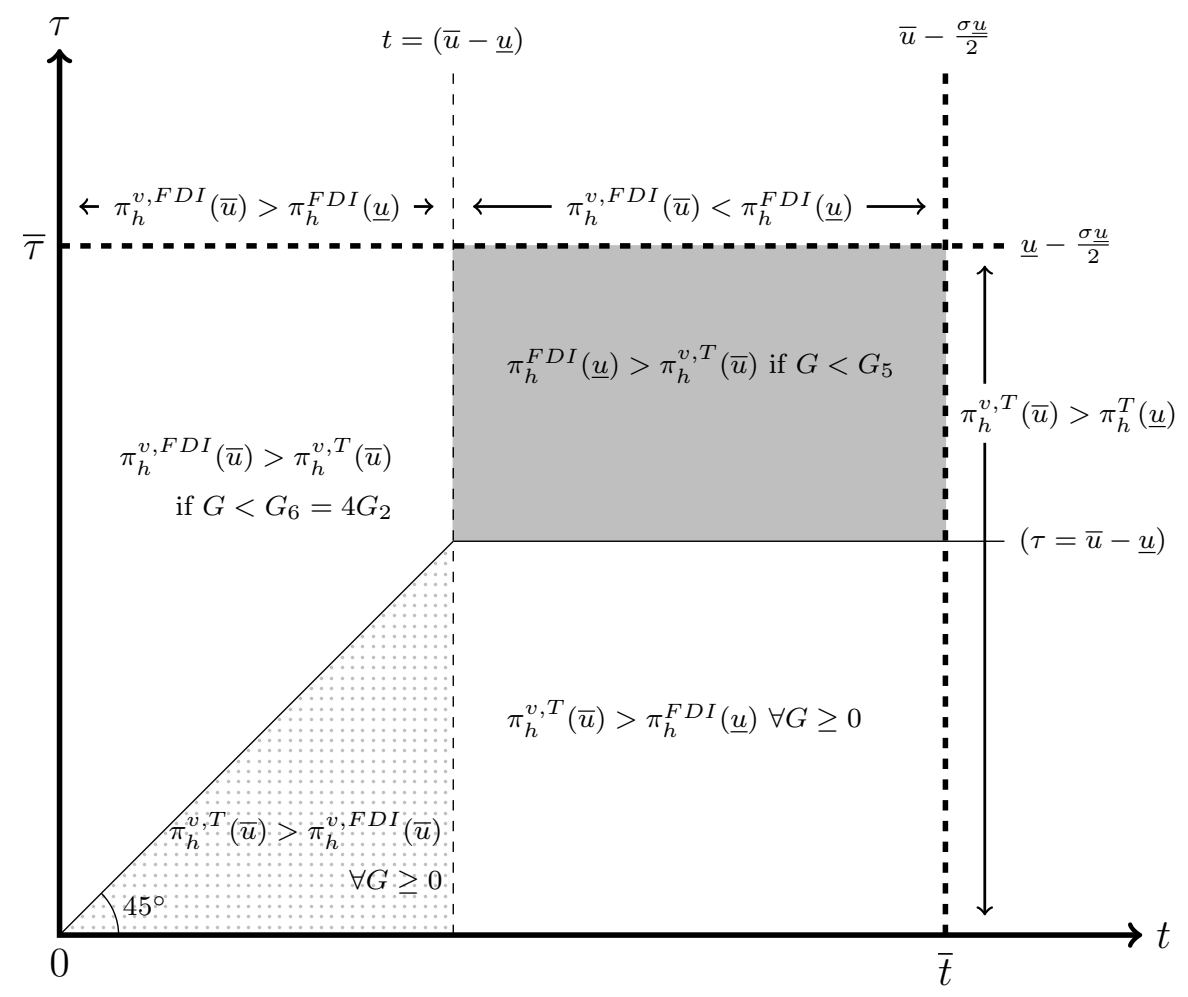

Figure 6: Vertical Integration; Relative product quality: $\bar{u} / \underline{u}<(4-\sigma) / 2$

timal for any constellation of trade and fixed investment costs. The choice is simply the optimal foreign market entry mode (exports vs. FDI), which is determined by trade and fixed investment costs. Also comparing Figures 4 and 5 with Figures 1 and 2 shows that when relative quality is high, avoiding double marginalization (by vertically integrating with the upstream monopoly) shifts the threshold value of input trade costs to the right. That is, for a larger range of input trade costs, high-quality subsidiary sales are more profitable than low-quality subsidiary sales. Similarly, when $\tau>t$ (the area above the 45-degree line, which is empirically relevant especially when physical trade costs are considered) vertical integration enables a multinational to manufacture high quality in equilibrium, even for larger values of fixed investment costs as the threshold value in the case of vertical integration $\left(G_{6}\right.$ given by Appendix A.7) is four times the threshold value in the case of upstream market power $\left(G_{2}\right.$ given by Appendix A.3).

When relative quality of the foreign variety is sufficiently low such that $\bar{u} / \underline{u}<(4-\sigma) / 2$, Figure 6 shows that low quality subsidiary sales can emerge as the equilibrium outcome (the shaded upper-right corner), especially when trade costs in final goods and inputs are both sufficiently large such that $(\tau, t)>>(\bar{u}-\underline{u})$ and fixed investment costs are sufficiently low (such that $G<G_{5}$, see Appendix A.7). That said, comparing 
Figures 3 and 6 shows that when there is upstream monopoly, this equilibrium outcome can emerge for greater values of threshold fixed investment costs (as $G_{3}>G_{5}$, see Appendix) and for a larger range of input trade costs (as well as for a larger range of trade costs in final goods especially when relative quality is not substantially low such that $(6-\sigma) / 4<\bar{u} / \underline{u}<(4-\sigma) / 2)$. In both cases, however, the probability of low-quality subsidiary sales increases with an increase in trade costs in final goods (as both $G_{3}$ and $G_{5}$ are positively related to $\tau$ given by Appendix A.4 and A.7). That said, it is also clear from Figure 6 (as compared to Figure 3) that avoiding double marginalization by vertical integration not only can make high quality subsidiary sales possible (see the area above the 45-degree line where $\tau>t$ and $t<(\bar{u}-\underline{u})$ ), but also manufacturing high quality in general more likely.

\section{Concluding remarks}

The trade literature agrees that there are large frictions against manufacturing highquality varieties. While the literature has already studied contract enforcement as part of such frictions, another empirically relevant case, upstream market power has been mostly overlooked. This study has employed a differentiated Cournot model with both vertical and horizontal product differentiation so as to delineate the implications of upstream market power in customized high-quality inputs (warranted for high-quality manufactures) on a downstream firm's endogenous foreign market entry mode (trade or FDI) and product quality choice (via choosing a particular input supplier). In particular, motivated by the statistical and anecdotal evidence reported by the empirical trade literature, this study has shown that upstream market power for high-quality inputs (i) generates important frictions and renders production of a differentiated high-quality final good costly, and (ii) has important trade policy implications for high-quality exports and subsidiary sales. The results have suggested that relative quality of the foreign variety is crucial. For sufficiently high relative quality, both trade and investment policy (decreasing trade and investment costs) can be effective in promoting high-quality exports and subsidiary sales.

Overall this study has led to new insights emphasizing the important role upstream market power can play for foreign market entry and product quality. In particular, building on the existing literature, this study has developed a theory model that takes into account large frictions against high-quality manufactures and that endogenizes both the foreign market entry mode choice and the choice of an input supplier (de- 
termining the quality of the foreign variety) so as to qualify and explain intuitively a number of empirical findings on trade and product quality. The discussions have been extended to the product quality choice of multinationals and FDI under upstream market power, which has been overlooked by the related trade and FDI literature. In this sense, this study significantly complements and contributes to the existing trade and FDI literature.

Of course, whether upstream market power generating large frictions against highquality manufactures matter or not for a particular industry is, in the end, an empirical question. Thus, to flesh out the role upstream market power plays in determining a foreign firm's optimal product quality and market entry mode choice, the model has been extended to vertical integration such that the integrated firm avoids the double marginalization problem. This has been also the standard approach in the existing literature. As might be expected, it has been shown that such a case would generate similar results as in the related trade literature, and would favor high quality manufactures across borders.

\section{Appendix}

\section{A.1 Proof of Proposition 1}

Comparing a multinational's profits from subsidiary sales of different quality, given by equations (3) and (5) shows that

$$
\lim _{t \rightarrow 0}\left[\pi_{h}^{F D I}(\bar{u}, \cdot)-\pi_{h}^{F D I}(\underline{u}, \cdot)\right]=\frac{(2 \bar{u}+(4-3 \sigma) \underline{u})((\bar{u}-\underline{u})-(\underline{u}-(\sigma \underline{u} / 2)))}{2\left(4-\sigma^{2}\right)^{2}},
$$

which is clearly negative for $(\bar{u} / \underline{u})<(4-\sigma) / 2 \Longleftrightarrow(\bar{u}-\underline{u})-(\underline{u}-(\sigma \underline{u} / 2))<0$. Moreover, $\partial\left[\pi_{h}^{F D I}(\bar{u}, \cdot)-\pi_{h}^{F D I}(\underline{u}, \cdot)\right] / \partial t<0$ for any $t<\bar{t}=\bar{u}-(\sigma \underline{u} / 2)$, and at $t=$ $(\bar{u}-\underline{u})-(\underline{u}-(\sigma \underline{u} / 2))<\bar{t},\left[\pi_{h}^{F D I}(\bar{u}, \cdot)-\pi_{h}^{F D I}(\underline{u}, \cdot)\right]=0$. Thus, for $(\bar{u} / \underline{u})>(4-\sigma) / 2$, $\left[\pi_{h}^{F D I}(\bar{u}, \cdot)-\pi_{h}^{F D I}(\underline{u}, \cdot)\right]>0$ so long as $t<(\bar{u}-\underline{u})-(\underline{u}-(\sigma \underline{u} / 2))$, whereas for $(\bar{u} / \underline{u})<$ $(4-\sigma) / 2,\left[\pi_{h}^{F D I}(\bar{u}, \cdot)-\pi_{h}^{F D I}(\underline{u}, \cdot)\right]<0$ for any $t<\bar{t}$ completing the proof. 


\section{A.2 Proof of Proposition 3}

Comparing an exporter's profits from its sales of different quality, given by equations (6) and (8) shows that

$$
\lim _{\tau \rightarrow 0}\left[\pi_{h}^{T}(\bar{u}, \cdot)-\pi_{h}^{T}(\underline{u}, \cdot)\right]=\frac{(2 \bar{u}+(4-3 \sigma) \underline{u})((\bar{u}-\underline{u})-(\underline{u}-(\sigma \underline{u} / 2)))}{2\left(4-\sigma^{2}\right)^{2}},
$$

which is clearly negative for $(\bar{u} / \underline{u})<(4-\sigma) / 2 \Longleftrightarrow(\bar{u}-\underline{u})-(\underline{u}-(\sigma \underline{u} / 2))<0$. When $\tau$ approaches to its prohibitive level $\bar{\tau}=\underline{u}-(\sigma \underline{u}) / 2$, this difference gets

$$
\lim _{\tau \rightarrow \bar{\tau}}\left[\pi_{h}^{T}(\bar{u}, \cdot)-\pi_{h}^{T}(\underline{u}, \cdot)\right]=\left(\frac{\bar{u}-\underline{u}}{4-\sigma^{2}}\right)^{2}
$$

which is positive. Note that $\partial\left[\pi_{h}^{T}(\bar{u}, \cdot)-\pi_{h}^{T}(\underline{u}, \cdot)\right] / \partial \tau>0$ at $\tau<\underline{u}-(\sigma \underline{u}) / 2-(\bar{u}-\underline{u}) / 3$, and that at $\tau=\underline{u}-(\sigma \underline{u}) / 2-(\bar{u}-\underline{u}),\left[\pi_{h}^{T}(\bar{u}, \cdot)-\pi_{h}^{T}(\underline{u}, \cdot)\right]=0$. It is now straightforward to show that, when $(\bar{u} / \underline{u})<(4-\sigma) / 2,\left[\pi_{h}^{T}(\bar{u}, \cdot)-\pi_{h}^{T}(\underline{u}, \cdot)\right]<0$ for $\tau<\underline{u}-(\sigma \underline{u}) / 2-(\bar{u}-\underline{u})$, and $\left[\pi_{h}^{T}(\bar{u}, \cdot)-\pi_{h}^{T}(\underline{u}, \cdot)\right]>0$ for $\underline{u}-(\sigma \underline{u}) / 2-(\bar{u}-\underline{u})<\tau<\bar{\tau}$. As for $(\bar{u} / \underline{u})>(4-\sigma) / 2$, $\left[\pi_{h}^{T}(\bar{u}, \cdot)-\pi_{h}^{T}(\underline{u}, \cdot)\right]>0$ at both $\tau=0$ and $\tau=\bar{\tau}$, and $\partial^{2}\left[\pi_{h}^{T}(\bar{u}, \cdot)-\pi_{h}^{T}(\underline{u}, \cdot)\right] / \partial \tau^{2}<0$, and thus $\left[\pi_{h}^{T}(\bar{u}, \cdot)-\pi_{h}^{T}(\underline{u}, \cdot)\right]>0$ for any $\tau<\bar{\tau}$, completing the proof.

\section{A.3 Proof of Proposition 5}

The fixed investment cost thresholds are such that $\pi_{h}^{F D I}(\underline{u}, \cdot)-\pi_{h}^{T}(\bar{u}, \cdot)=0$ at $G=G_{1}$, and $\pi_{h}^{F D I}(\bar{u}, \cdot)-\pi_{h}^{T}(\bar{u}, \cdot)=0$ at $G=G_{2}$, where

$$
\begin{aligned}
G_{1} & =\frac{(\tau-((\bar{u}-\underline{u})-(\underline{u}-(\sigma \underline{u} / 2))))((\bar{u}+(1-\sigma) \underline{u}+(\underline{u}-(\sigma \underline{u} / 2))-\tau)}{\left(4-\sigma^{2}\right)^{2}} \\
G_{2} & =\frac{(\tau-t)(2 \bar{u}-\sigma \underline{u}-(\tau+t))}{\left(4-\sigma^{2}\right)^{2}} .
\end{aligned}
$$

$\pi_{h}^{F D I}(\underline{u}, \cdot)-\pi_{h}^{T}(\bar{u}, \cdot)>0$ when $G<G_{1}$, and $\pi_{h}^{F D I}(\bar{u}, \cdot)-\pi_{h}^{T}(\bar{u}, \cdot)>0$ when $G<G_{2}$, where $G_{1} \geq 0$ if (and only if) $\tau \geq((\bar{u}-\underline{u})-(\underline{u}-(\sigma \underline{u} / 2)))$, and $G_{2} \geq 0$ if (and only if) $\tau \geq t$, completing the proof. As for the changes in the fixed investment cost thresholds:

$$
\begin{array}{ll}
\frac{\partial G_{1}}{\partial \tau}=\frac{2 \bar{u}-\sigma \underline{u}-2 \tau}{\left(4-\sigma^{2}\right)^{2}}>0, \quad \forall \tau<\bar{\tau} ; \quad \frac{\partial G_{1}}{\partial t}=0 \\
\frac{\partial G_{2}}{\partial \tau}=\frac{2 \bar{u}-\sigma \underline{u}-2 \tau}{\left(4-\sigma^{2}\right)^{2}}>0, \quad \forall \tau<\bar{\tau} ; \quad \frac{\partial G_{2}}{\partial t}=-\frac{2 \bar{u}-\sigma \underline{u}-2 t}{\left(4-\sigma^{2}\right)^{2}}<0, \quad \forall t<\bar{t}
\end{array}
$$

Note that the prohibitive cost thresholds are such that $\bar{\tau}=\underline{u}-\sigma \underline{u} / 2$ and $\bar{t}=\bar{u}-\sigma \underline{u} / 2$. 


\section{A.4 Proof of Proposition 6}

The fixed investment cost thresholds are such that $\pi_{h}^{F D I}(\underline{u}, \cdot)-\pi_{h}^{T}(\bar{u}, \cdot)=0$ at $G=G_{3}$, and $\pi_{h}^{F D I}(\underline{u}, \cdot)-\pi_{h}^{T}(\underline{u}, \cdot)=0$ at $G=G_{4}$, where

$$
\begin{aligned}
G_{3} & =\frac{(\tau+((\underline{u}-(\sigma \underline{u} / 2))-(\bar{u}-\underline{u})))((\bar{u}+(1-\sigma) \underline{u}+(\underline{u}-(\sigma \underline{u} / 2))-\tau)}{\left(4-\sigma^{2}\right)^{2}} \\
G_{4} & =\frac{4 \tau((2-\sigma) \underline{u}-\tau)}{\left(4-\sigma^{2}\right)^{2}} .
\end{aligned}
$$

$\pi_{h}^{F D I}(\underline{u}, \cdot)-\pi_{h}^{T}(\bar{u}, \cdot)>0$ when $G<G_{3}$, and $\pi_{h}^{F D I}(\underline{u}, \cdot)-\pi_{h}^{T}(\underline{u}, \cdot)>0$ when $G<G_{4}$, completing the proof. As for the changes in the fixed investment cost thresholds:

$$
\begin{array}{clrl}
\frac{\partial G_{3}}{\partial \tau}=\frac{2 \bar{u}-\sigma \underline{u}-2 \tau}{\left(4-\sigma^{2}\right)^{2}}>0, & \forall \tau<\bar{\tau} ; & \frac{\partial G_{3}}{\partial t}=0 \\
\frac{\partial G_{4}}{\partial \tau}=\frac{4(2-\sigma) \underline{u}-8 \tau}{\left(4-\sigma^{2}\right)^{2}}>0, & \forall \tau<\bar{\tau} ; & \frac{\partial G_{4}}{\partial t}=0
\end{array}
$$

Note that the prohibitive cost thresholds are such that $\bar{\tau}=\underline{u}-\sigma \underline{u} / 2$ and $\bar{t}=\bar{u}-\sigma \underline{u} / 2$.

\section{A.5 Proof of Proposition 7}

Comparing a multinational's profits from subsidiary sales of different quality (in the case that high quality products are manufactured through vertical integration), given by equations (3) and (9) shows that

$$
\pi_{h}^{v, F D I}(\bar{u}, \cdot)-\pi_{h}^{F D I}(\underline{u}, \cdot)=\frac{4((\bar{u}-\underline{u})-t)((\bar{u}+(1-\sigma) \underline{u}-t)}{\left(4-\sigma^{2}\right)^{2}},
$$

which is clearly positive if $t<(\bar{u}-\underline{u})$, and negative if otherwise, given input trade costs are below their prohibitive levels such that $t<\bar{t}=\bar{u}-\sigma \underline{u} / 2$, completing the proof of ( $i$ ). Replacing $t$ by $c+t$ in profits given by eq. (9) leads to a difference in profits given above, in which $t$ should be replaced by $c+t$ (and assuming away prohibitive costs should follow $c+t<\bar{u}-\sigma \underline{u} / 2)$. Thus, in such a case, $\pi_{h}^{v, F D I}(\bar{u}, \cdot)>\pi_{h}^{F D I}(\underline{u}, \cdot)$ if $c<$ $(\bar{u}-\underline{u})-t$, completing the proof of $(i i)$. Similarly, including fixed costs specific to vertical integration in profits given by eq. (9) leads to a fixed costs threshold (e.g., $\bar{C}$ ), such that $\pi_{h}^{v, F D I}(\bar{u}, \cdot)-\pi_{h}^{F D I}(\underline{u}, \cdot)=0$ at $\bar{C}$ which is given by the displayed equation above. Consequently, $\pi_{h}^{v, F D I}(\bar{u}, \cdot)-\pi_{h}^{F D I}(\underline{u}, \cdot)>0$ for fixed costs smaller than $\bar{C}$, completing the proof of $(i i i)$. 


\section{A.6 Proof of Proposition 8}

Comparing an exporter's profits from its sales of different quality (in the case that high quality products are manufactured through vertical integration), given by equations (6) and 10 shows that

$$
\pi_{h}^{v, T}(\bar{u}, \cdot)-\pi_{h}^{T}(\underline{u}, \cdot)=\frac{4(\bar{u}-\underline{u})(\bar{u}+(1-\sigma) \underline{u}-2 \tau)}{\left(4-\sigma^{2}\right)^{2}},
$$

which is clearly positive for any non-prohibitive trade costs in final goods such that $\bar{\tau}<\bar{\tau}=\underline{u}-\sigma \underline{u} / 2$. In the case that vertical integration warrants some variable costs, $\tau$ in profits given by eq. (10) should be replaced by $c+\tau$. In the case of additional variable costs (where prohibitive costs would be assumed away such that $c+\tau<\underline{u}-\sigma \underline{u} / 2$ ), the difference between profits would be

$$
\pi_{h}^{v, T}\left(c_{h}, \bar{u}, \cdot\right)-\pi_{h}^{T}\left(c_{h}, \underline{u}, \cdot\right)=\frac{4((\bar{u}-\underline{u})-c)(\bar{u}+(1-\sigma) \underline{u}-2 \tau-c)}{\left(4-\sigma^{2}\right)^{2}},
$$

which is clearly positive for $c<(\bar{u}-\underline{u})$. If vertical integration warrants some additional fixed costs (e.g., $\bar{C}$ ), then this should be subtracted from profits given by eq. 10. In such a case, depending on whether or not there is an additional variable cost (due to vertical integration), either of the two expressions above will be the threshold fixed cost below which exporting a high-quality foreign variety will be preferred over exporting a low-quality foreign variety, completing the proof.

\section{A.7 Proof of Proposition 10}

Propositions 7 and 8 and Appendix A.5 and A.6 have already shown that producing a high-quality foreign variety is optimal for any non-prohibitive trade costs for an exporter, whereas a multinational prefers manufacturing high quality only if $t<(\bar{u}-\underline{u})$. That is, so as to determine the equilibrium outcome, when $t<(\bar{u}-\underline{u}), \pi_{h}^{v, F D I}(\bar{u}, \cdot)$ and $\pi_{h}^{v, T}(\bar{u} \cdot)$ has to be compared, whereas when $t>(\bar{u}-\underline{u}), \pi_{h}^{F D I}(\underline{u}, \cdot)$ and $\pi_{h}^{v, T}(\bar{u} \cdot)$ has to be compared. This leads to the fixed investment cost thresholds such that $\pi_{h}^{F D I}(\underline{u}, \cdot)-$ $\pi_{h}^{v, T}(\bar{u}, \cdot)=0$ at $G=G_{5}$, and $\pi_{h}^{v, F D I}(\bar{u}, \cdot)-\pi_{h}^{v, T}(\bar{u}, \cdot)=0$ at $G=G_{6}$, where

$$
\begin{aligned}
G_{5} & =\frac{4(\tau-(\bar{u}-\underline{u}))((\bar{u}+(1-\sigma) \underline{u}-\tau)}{\left(4-\sigma^{2}\right)^{2}} \\
G_{6} & =\frac{4(\tau-t)(2 \bar{u}-\sigma \underline{u}-(\tau+t))}{\left(4-\sigma^{2}\right)^{2}}=4 G_{2} .
\end{aligned}
$$


$\pi_{h}^{F D I}(\underline{u}, \cdot)-\pi_{h}^{v, T}(\bar{u}, \cdot)>0$ when $G<G_{5}$, and $\pi_{h}^{v, F D I}(\bar{u}, \cdot)-\pi_{h}^{v, T}(\bar{u}, \cdot)>0$ when $G<G_{6}$, where $G_{5} \geq 0$ if (and only if) $\tau \geq\left(\bar{u}-\underline{u}\right.$ ), and $G_{6} \geq 0$ if (and only if) $\tau \geq t$, completing the proof. As for the changes in the fixed investment cost thresholds:

$$
\begin{array}{ll}
\frac{\partial G_{5}}{\partial \tau}=\frac{4(2 \bar{u}-\sigma \underline{u}-2 \tau)}{\left(4-\sigma^{2}\right)^{2}}>0, \quad \forall \tau<\bar{\tau} ; \quad \frac{\partial G_{5}}{\partial t}=0 \\
\frac{\partial G_{6}}{\partial \tau}=\frac{4(2 \bar{u}-\sigma \underline{u}-2 \tau)}{\left(4-\sigma^{2}\right)^{2}}>0, \quad \forall \tau<\bar{\tau} ; \quad \frac{\partial G_{6}}{\partial t}=-\frac{4(2 \bar{u}-\sigma \underline{u}-2 t)}{\left(4-\sigma^{2}\right)^{2}}<0, \quad \forall t<\bar{t}
\end{array}
$$

Note that the prohibitive cost thresholds are such that $\bar{\tau}=\underline{u}-\sigma \underline{u} / 2$ and $\bar{t}=\bar{u}-\sigma \underline{u} / 2$.

\section{References}

[1] Acharyya, R. 1998. Monopoly and product quality separating or pooling menu? Economics Letters 61: 187-194.

[2] Acharyya, R. 2005. Quality discrimination among income constrained consumers. Economics Letters 86: 245-251.

[3] Alchian, A., Allen, W.R. 1964. University economics. Belmont CA: Wadsworth Publishing

[4] Anderson, S.P., Schmitt, N. 2010. Differentiated products, international trade and simple general equilibrium effects. In G.Dow, A.Eckert \& D. West (eds), Industrial Organization, Trade and Social Interaction: Essays in Honor of B. Curtis Eaton, pp. 136-159 (Chapter 7). University of Toronto Press.

[5] Antoniades, A. 2015. Heterogeneous firms, quality, and trade. Journal of International Economics 95: 263-273.

[6] Amiti, M., Khandelwal, A. 2013. Import competition and quality upgrading. Review of Economics and Statistics 95: 476-490.

[7] Antràs, P. 2016. Global Production: Firms, Contracts, and Trade Structure. Princeton University Press.

[8] Antràs, P. 2003. Firms, contracts, and trade structure. Quarterly Journal of Economics 118: 1375-1418.

[9] Antràs, P., Helpman E. 2004. Global sourcing. Journal of Political Economy 112: $552-580$.

[10] Antràs, P., Staiger, R.W. 2012. Offshoring and the Role of Trade Agreements. American Economic Review 102: 3140-3183.

[11] Antràs, P., Yeaple, S.R. 2014. Multinational firms and the structure of international trade. In G. Gopinath, E. Helpman, K. Rogoff (Eds.), Handbook of International Economics 4: 55-130. 
[12] Arnold, J.M., Hussinger, K. 2010. Exports versus FDI in German manufacturing: firm performance and participation in international markets. Review of International Economics 18: 595-606.

[13] Aw, B., Lee, Y. 2008. Firm heterogeneity and location choice for Taiwanese multinationals. Journal of International Economics 75: 67-179.

[14] Atkeson, A., Burstein, A.T. 2010. Innovation, firm Dynamics, and international trade. Journal of Political Economy 118: 433-484.

[15] Bacchiega, E., Minniti, A., Palestini, A. 2016. Quality, distance and trade: a strategic approach. Papers in Regional Science 95 (Supplement 1): S166-S191.

[16] Baldwin, R., Harrigan, J. 2011. Zeros, quality and space: trade theory and trade evidence. American Economic Journal: Microeconomics 3: 60-88.

[17] Banerjee T., Nayak A. 2017. Multinational investments and product sophistication. Economics Letters 161: 157-163.

[18] Bastos, P., Silva, J. 2010. The quality of a firm's exports: where you export to matters. Journal of International Economics 82: 99-111.

[19] Bastos, P., Straume, O.R. 2012. Globalization, product differentiation, and wage inequality. Canadian Journal of Economics 45(3): 857-878.

[20] Boddin, D., Stähler, F. 2018. The organization of international trade. Mimeo.

[21] Braun, S. 2008. Economic integration, process and product Innovation, and relative skill demand. Review of International Economics 16(5): 864-873.

[22] Castellani, D., Giovannetti, G. 2010. Productivity and the international firm: dissecting heterogeneity. Journal of Economic Policy Reform 13: 25-42.

[23] Castellani, D., Zanfei, A. 2007. Internationalisation, innovation and productivity: how do firms differ in Italy? World Economy 30, 156-176.

[24] Choi, J.C., Shin, H.S. 1992. A comment on a model of vertical product differentiation. Journal of Industrial Economics 60: 229-231.

[25] Crampes, C., Hollander, A. 1995. Duopoly and quality standards. European Economic Review 39: 71-82.

[26] Crozet, M., Head, K., Mayer, T. 2012. Quality sorting and trade: firm-level evidence for French wine. Review of Economic Studies 79: 609-644.

[27] De Fraja, G., Norman, G. 2004. Product differentiation and the location of international production. Journal of Economics and Management Strategy 13(1): 151-170.

[28] Fajgelbaum, P., Grossman, G., Helpman, E. 2011. Income distribution, product quality, and international trade. Journal of Political Economy 119: 721-765. 
[29] Falvey R.E., Kierzkowski, H. 1987. Product quality, intra-industry trade and (im)perfect competition. In H. Kierzkowski (ed.), Protection and Competition in International Trade, pp. 143-161, New York: Basil Blackwell.

[30] Feenstra, R., Romalis, J. 2014. International prices and endogenous quality. Quarterly Journal of Economics 129: 477-527.

[31] Flam, H., Helpman, E. 1987. Vertical product differentiation and North-South trade. American Economic Review 77(5): 810-822.

[32] Gabszewicz, J., Thisse, J.F. 1979. Price competition, quality and income disparities. Journal of Economic Theory 20: 310-335.

[33] Girma, S., Görg, H., Strobl, E. 2004. Exports, international investment, and plant performance: evidence from a non-parametric test. Economics Letters 83: 317-324.

[34] Girma, S., Kneller, R., Pisu, M. 2005. Exports versus FDI: an empirical test. Review of World Economics 141: 193-218.

[35] Greenaway, D., Kneller, R. 2007. Firm heterogeneity, exporting and foreign direct investment. Economic Journal 117: 134-161.

[36] Hallak, J., Sivadasan, J. 2013. Firm's exporting behavior under quality constraints. Journal of International Economics 91(1): 53-67.

[37] Hayakawa, K., Machikita, T., Kimura, F. 2012. Globalization and productivity: a survey of firm-level analysis. Journal of Economic Surveys 26: 332-350.

[38] Häckner, J. 2000. A note on price and quantity competition in differentiated oligopolies. Journal of Economic Theory 93: 233-239.

[39] Helpman, E., Melitz, M.J., Yeaple, S.R. 2004. Export versus FDI with heterogeneous firms. American Economic Review 94: 300-316.

[40] Iacovone, L., Javorcik, B. 2010. Multi-product exporters: product churning, uncertainty and export discoveries. Economic Journal 120(544), 481-499.

[41] Johnson, R., 2012. Trade and prices with heterogeneous firms. Journal of International Economics 86(1), 43-56.

[42] Kim, J.H., Kim, J.C. 1996. Quality choice of multi-product monopolist and spillover effect. Economics Letters 52: 345-352.

[43] Kimura, F., Kiyota, K. 2006. Exports, FDI, and productivity: dynamic evidence from Japanese firms. Review of World Economics 142: 695-719.

[44] Koska, O.A. 2015. A model of competition between multinationals. METU Studies in Development 42(2): 271-298.

[45] Kugler, M., Verhoogen, E. 2012. Prices, plant size, and product quality. Review of Economic Studies 79: 307-339. 
[46] Linder, S.B. 1961. An Essay on Trade and Transformation. Stockholm: Almqvist and Wiksell.

[47] Mai, J., Zhou, J. 2017. A note on foreign direct investment and exports in vertically differentiated industries. Bulletin of Economic Research 69(2): 138-146.

[48] Manova, K., Yu, Z. 2017. Multi-product firms and product quality. Journal of International Economics 109: 116-137.

[49] Manova, K., Zhang, Z. 2012. Export prices across firms and destinations. Quarterly Journal of Economics 127: 379-436.

[50] Markusen, J.R. 2002. Multinational firms and the theory of international trade. Cambridge: The MIT Press.

[51] Mayer, T., Ottaviano, G.I.P. 2008. The happy few: the internationalisation of European firms. Intereconomics: Review of European Economic Policy 43: 135148.

[52] Melitz, M.J. 2003. The impact of trade on intra-industry reallocations and aggregate industry productivity. Econometrica 71: 1695-1725.

[53] Motta, M. 1993. Endogenous quality choice: price vs. quantity competition. Journal of Industrial Economics 41(2): 113-131.

[54] Motta, M. 1994. International trade and investments in a vertically differentiated industry, International Journal of Industrial Organization 12: 179-196.

[55] Motta, M., Thisse, J-F., Cabrales, A. 1997. On the persistence of leadership or leapfrogging in international trade. International Economic Review 38(4): 809-824.

[56] Mussa, M., Rosen, S. Monopoly and product quality. Journal of Economic Theory 18: 301-317.

[57] Nabin, M.H., Nguyen, X., and Sgro, P.M. 2013. Technology transfer, quality standards, and NorthâĂŞSouth trade. Review of International Economics 21(4): 783796.

[58] Navaretti, G.B., Venables, A.J. 2004. Multinational Firms in the World Economy. Princeton University Press.

[59] Nunn, N. 2007. Relationship-specificity, incomplete contracts, and the pattern of trade. Quarterly Journal of Economics 122: 569-600.

[60] Rauch, J.E. 1999. Networks versus markets in international trade. Journal of International Economics 48: 7-35.

[61] Schmitt, N. 1995. Product imitation, product differentiation, and international trade. International Economic Review 36: 583-608.

[62] Shaked, A., Sutton, J. 1982. Relaxing price competition through product differentiation. Review of Economic Studies 49: 3-13. 
[63] Singh, N., Vives, X. 1984. Price and quantity competition in a differentiated oligopoly. RAND Journal of Economics 15: 546-554.

[64] Symeonidis, G. 2003. Comparing Cournot and Bertrand equilibria in a differentiated duopoly with product R\&D. International Journal of Industrial Organization 21: $39-55$.

[65] Tirole, J. 1988. The Theory of Industrial Organization. Cambridge, MA: The MIT Press.

[66] Tomiura, E. 2007. Foreign outsourcing, exporting, and FDI: a productivity comparison at the firm level. Journal of International Economics 72: 113-127.

[67] Toshimutsu, T. 2005. Tariffs, quality choice, and cost functions: a foreign monopoly case. Review of International Economics 13(2): 376-384.

[68] Verhoogen, E. 2008. Trade, quality upgrading and wage inequality in the Mexican manufacturing sector. Quarterly Journal of Economics 123: 489-530.

[69] Wagner, J. 2006. Exports, foreign direct investment, and productivity: evidence from German firm level data. Applied Economics Letters 13: 347-349.

[70] Wagner, J. 2007. Exports and productivity: a survey of the evidence from firm-level data. World Economy 30: 60-82.

[71] Wagner, J. 2012. International trade and firm performance: a survey of empirical studies since 2006. Review of World Economics 148: 235-267.

[72] Wauthy, X. 1996. Quality choice in the model of vertical differentiation. Journal of Industrial Economics 44: 345-353. 